\title{
BMJ Open Impact of disasters, including pandemics, on cardiometabolic outcomes across the life-course: a systematic review
}

\author{
Vanessa De Rubeis (D , ${ }^{1}$ Jinhee Lee, ${ }^{1}$ Muhammad Saqib Anwer, ${ }^{1}$ \\ Yulika Yoshida-Montezuma, ${ }^{1}$ Alessandra T Andreacchi (D) , ${ }^{1}$ Erica Stone, ${ }^{1}$ \\ Saman Iftikhar, ${ }^{1}$ Jason D Morgenstern, ${ }^{1}$ Reid Rebinsky, ${ }^{1,2}$ \\ Sarah E Neil-Sztramko (D) , ${ }^{1,3}$ Elizabeth Alvarez (D) , ${ }^{1,4}$ Emma Apatu, ${ }^{1,4}$ \\ Laura N Anderson (10) 1,4
}

To cite: De Rubeis V, Lee J, Anwer MS, et al. Impact of disasters, including pandemics, on cardiometabolic outcomes across the life-course: a systematic review. BMJ Open 2021;11:e047152. doi:10.1136/ bmjopen-2020-047152

- Prepublication history and supplemental material for this paper is available online. To view these files, please visit the journal online (http://dx.doi org/10.1136/bmjopen-2020047152).

Received 19 November 2020 Revised 27 March 2021 Accepted 29 March 2021

Check for updates

(c) Author(s) (or their employer(s)) 2021. Re-use permitted under CC BY-NC. No commercial re-use. See rights and permissions. Published by BMJ.

For numbered affiliations see end of article.

Correspondence to

Dr Laura N Anderson;

In.anderson@mcmaster.ca

\section{ABSTRACT}

Background Disasters are events that disrupt the daily functioning of a community or society, and may increase long-term risk of adverse cardiometabolic outcomes, including cardiovascular disease, obesity and diabetes. The objective of this study was to conduct a systematic review to determine the impact of disasters, including pandemics, on cardiometabolic outcomes across the lifecourse.

Design A systematic search was conducted in May 2020 using two electronic databases, EMBASE and Medline. All studies were screened in duplicate at title and abstract, and full-text level. Studies were eligible for inclusion if they assessed the association between a population-level or community disaster and cardiometabolic outcomes $\geq 1$ month following the disaster. There were no restrictions on age, year of publication, country or population. Data were extracted on study characteristics, exposure (eg, type of disaster, region, year), cardiometabolic outcomes and measures of effect. Study quality was evaluated using the Joanna Briggs Institute critical appraisal tools.

Results A total of 58 studies were included, with 24 studies reporting the effects of exposure to disaster during pregnancy/childhood and 34 studies reporting the effects of exposure during adulthood. Studies included exposure to natural $(n=35 ; 60 \%)$ and human-made $(n=23 ; 40 \%)$ disasters, with only three $(5 \%)$ of these studies evaluating previous pandemics. Most studies reported increased cardiometabolic risk, including increased cardiovascular disease incidence or mortality, diabetes and obesity, but not all. Few studies evaluated the biological mechanisms or high-risk subgroups that may be at a greater risk of negative health outcomes following disasters.

Conclusions The findings from this study suggest that the burden of disasters extend beyond the known direct harm, and attention is needed on the detrimental indirect long-term effects on cardiometabolic health. Given the current COVID-19 pandemic, these findings may inform public health prevention strategies to mitigate the impact of future cardiometabolic risk.

PROSPERO registration number CRD42020186074.

\section{Strengths and limitations of this study}

- This systematic review is one of the first to review the literature on disasters, including pandemics, and subsequent cardiometabolic outcomes throughout the life-course.

- A comprehensive search strategy was used to identify studies that covered a range of disasters (eg, famine, war, terrorism, natural disasters and infectious disease epidemics), periods of exposure from pregnancy, childhood to older adulthood and a wide breadth of cardiometabolic outcomes.

- Only studies published in English were included and a search of the grey literature was not conducted.

- Due to the heterogeneity of studies, a meta-analysis could not be conducted, and results were only synthesised narratively.

- Limited evidence was available on the impact of pandemics specifically, and few studies evaluated proposed mechanisms or risk modification across subgroups of the populations.

\section{BACKGROUND}

Disasters, as defined by the WHO, are events that disrupt the daily functioning of a community or society causing material, economic or environmental losses, overwhelming local capacity. ${ }^{1}$ Disasters can be categorised into natural disasters, human-made disasters and hybrid disasters. ${ }^{2}$ Natural disasters include natural phenomenon above and beneath the earth's surface (eg, tsunamis or landslides), meteorological phenomenon (eg, tornadoes or floods) or biological phenomenon (eg, epidemics and pandemics). ${ }^{2}$ Human-made disasters include adverse transportation incidents, technological events (eg, fire or toxic leaks), terrorism, warfare or conflict. ${ }^{2}$ A hybrid disaster results from both human 
and natural forces, such as the clearing of a jungle that results in a landslide. ${ }^{2}$ All types of disasters can result in public health emergencies as they typically impact a significant proportion of people. ${ }^{3}$ Epidemics, defined as a greater than expected increase in cases of a disease, and pandemics, which cross countries and continents, are types of natural disasters with far-reaching global disruption. ${ }^{4}$ The COVID-19 pandemic is a present-day example of a global disaster that is unlike any disaster in recent history. Understanding the potential long-term health implications of the current COVID-19 pandemic and resulting public health mitigation strategies is urgently needed.

Previous systematic reviews have focused on acute outcomes, specifically on the psychological impact of quarantine during pandemics, ${ }^{5}$ the impact on health outcomes after disasters in older adults, ${ }^{6}$ medically unexplained physical symptoms following disasters ${ }^{7}$ and chronic medical interventions following a natural disaster. $^{8}$ It is biologically plausible that exposure to a disaster may lead to long-term or chronic outcomes that could arise many years later and this may be modified by the time of exposure across the life-course. Consistent with established models of life-course epidemiology, there may be critical periods of exposure (eg, during development in childhood), where exposure to a disaster substantially increases later life disease risk, or exposure to a disaster may contribute to a chain of risk or accumulation of risks across the life-course. ${ }^{9}{ }^{10}$ There is currently no review on the long-term impacts of disasters, or more specifically, epidemics and pandemics on cardiometabolic outcomes across the life-course. Noncommunicable diseases (NCDs), including cardiovascular disease (CVD), obesity and diabetes, are the leading cause of morbidity and mortality worldwide. ${ }^{11}{ }^{12}$ NCDs are attributed to $71 \%$ of all global deaths annually, with approximately 14 million CVD-related deaths and 1.6 million diabetes-related deaths. ${ }^{12}$ Findings from the Global Burden of Diseases Study indicate that CVD and diabetes account for over $20 \%$ of the global burden of disability, with diabetes recently emerging as the fourth leading cause of disability globally. ${ }^{11}$ Exposure to disasters may cause cardiometabolic outcomes to emerge or worsen through several different mechanistic pathways including stress exposure, ${ }^{13}$ lack of access to health services, ${ }^{14}$ food security, and behavioural changes such as alterations in physical activity, sleep and diet. ${ }^{15}$ It is important to understand the impact of disasters on the incidence of new cardiometabolic diseases and changes in disease status in all populations and age groups. Particular subgroups of a population may be more or less susceptible to cardiometabolic outcomes and understanding this can inform targeted interventions. The primary objective of this review was to determine the impact of disasters, including pandemics on risk of cardiometabolic outcomes across the life-course. The secondary objectives were to determine how to reduce the impact of chronic disease outcomes following a disaster and to identify populations

\begin{tabular}{lr}
\hline Table 1 Search strategy for EMBASE & \\
\hline 1 social isolation.mp. or social isolation/ & 24963 \\
\hline 2 quarantine.mp. or quarantine/ & 4752 \\
\hline *epidemic/ & 32686 \\
\hline 4 *pandemic/ & 4387 \\
\hline 5 disease outbreak.mp. & 2321 \\
\hline 6 disaster/ & 13321 \\
\hline 7 *natural disaster/ & 968 \\
\hline 8 humanitarian crisis.mp. & 257 \\
\hline 9 mass casuality.mp. or mass disaster/ & 3654 \\
\hline 10 coronavirus.mp. or coronaviridae/ & 23106 \\
\hline 11 cardiovascular disease.mp. or & 357319 \\
${ }^{*}$ cardiovascular disease/ & \\
\hline 12 *diabetes mellitus/ & 210248 \\
\hline 13 *cerebrovascular accident/ & 78444 \\
\hline 14 *heart infarction/ & 99072 \\
\hline 15 *angina pectoris/ & 22631 \\
\hline 16 *obesity/ & 178134 \\
\hline 17 public health emergency.mp. & 1752 \\
\hline 18 *body mass/ & 31459 \\
\hline 19 *hypertension/ & 198593 \\
\hline 21 or 2 or 3 or 4 or 5 or 6 or 7 or 8 or 9 & 109105 \\
\hline or 19 & \\
\hline 22 limit 22 to human 12 or 13 or 14 or 15 or 16 or 18 & 1087681 \\
\hline & \\
\hline
\end{tabular}

at highest risk of cardiometabolic outcomes following a disaster.

\section{METHODS}

A systematic review was conducted following the Preferred Reporting Items for Systematic Reviews and Meta-Analyses. ${ }^{16}$

\section{Search strategy}

A systematic search was conducted in May 2020 using the electronic databases EMBASE and MEDLINE. The health research librarians at McMaster University assisted in developing the search strategy. The search broadly captured two concepts: disasters and cardiometabolic outcomes (eg, diabetes, obesity, hypertension). The complete search strategy for EMBASE can be found in table 1. The search strategy for MEDLINE can be found in the online supplemental table A1. Reference lists of eligible studies and relevant systematic reviews were hand searched to identify additional articles.

\section{Eligibility criteria}

Studies were eligible for inclusion if they assessed the relationship between a population level or community disaster and the risk of future cardiometabolic outcomes 
including CVD, diabetes or obesity or cardiometabolic risk scores. ${ }^{17}$ CVD included myocardial infarction, stroke, hypertension and angina. There were no restrictions on year of publication, country of disaster or population. Only studies evaluating the impact of real-world disasters in humans were included. Due to the research team's capacity, only studies published in English were included. Observational and quasiexperimental study designs, including case-control, cohort and other longitudinal study designs or natural experiments, were included. Outcomes that were not cardiometabolic related or acute cardiometabolic events, such as an immediate complication (defined as $<1$ month after disaster), were excluded. Studies that assessed the exposure to a chemical as a result of the disaster were excluded, as we were not interested in outcomes resulting from chemical exposure. Earthquake studies were also excluded since a systematic review was published in 2018 that assessed the impact of earthquakes on cardiometabolic outcomes. ${ }^{18}$

\section{Study selection}

After running the search, all identified studies were imported into Covidence and duplicates were removed. ${ }^{19}$ Studies were screened at title and abstract level, and then at full text by any two of the following independent reviewers: VDR, JL, MSA, YY-M, ATA, ES, SI, JDM, RR, LNA. Conflicts were resolved by a third reviewer who made the final decision regarding eligibility for inclusion.

\section{Data extraction}

A data extraction template was created and pilot tested prior to data extraction. Data were then extracted from all studies by any two of the following independent abstractors: VDR, JL, MSA, YY-M, ATA, RR, ES and conflicts were resolved by a third independent abstractor. Study characteristics including year of publication, study design, country of disaster, sample size and length of study were extracted where reported. Specific information on the exposure and outcome in each study was extracted including the type and name of the disaster, country and year of the disaster, the outcome of interest, and how the exposure and outcome were measured. Finally, any information on subgroups including age, population, sex and disaster type was also extracted, if applicable.

\section{Critical appraisal}

Critical appraisal was conducted using the Joanna Briggs Institute Critical Appraisal Tools. ${ }^{20}$ This tool was chosen due to the availability of checklists for a wide range of study designs, including cohort, cross-sectional and quasi-experimental designs. ${ }^{20}$ The quasi-experimental study design checklist was used for natural experiments including time-series studies and pre/post-designs, as it was decided this was the most appropriate tool. All studies were critically appraised independently by any two of the following individuals: VDR, JL, MSA, YY-M, ATA, ES, SI, and a third individual was consulted for any discrepancies.

\section{Data analysis}

Data from the included studies were narratively synthesised. Results are presented by exposure period (perinatal/childhood vs adulthood) and by cardiometabolic outcome (obesity, CVD and diabetes). Characteristics of studies are presented as frequencies and percentages. Due to the heterogeneity of studies, a meta-analysis was not conducted.

\section{RESULTS}

A total of 4830 studies were identified through the electronic database search. An additional 12 studies were identified through manual searching of the reference lists of relevant studies. After removing duplicates $(n=439), 4403$ studies were screened at title and abstract level. After applying inclusion and exclusion criteria, 4068 studies were excluded, leaving 335 studies screened for full-text eligibility. A total of 58 studies were eligible for inclusion into the review. The complete screening process is described in figure 1.

\section{Description of studies}

Table 2 provides a summary of included studies. Of 58 included studies, 24 studies ${ }^{15}$ 21-43 investigated exposure to disasters during pregnancy or childhood while the remaining 34 studies $^{14} 44-76$ investigated exposure to disaster during adulthood. Almost all studies $(\mathrm{n}=49)$ assessed cardiometabolic outcomes during adulthood, only two studies assessed outcomes during pregnancy ${ }^{27} 28$ and seven studies assessed outcomes during childhood and adolescence. ${ }^{15}$ 21-26 The length of studies, including prospective follow-up and retrospective assessment, ranged from 1 month to 95 years. Most studies $(n=36)$ focused on disasters that occurred in North America, ${ }^{1421-2838394245-495152545557-6063-6567-727576}$ followed by Europe $(n=13) .{ }^{29-33} 35414353627374$ The remaining disasters occurred in Asia (n=7) 15374044505661 and Africa $(\mathrm{n}=2) .{ }^{36} 66$ The characteristics of included studies and key findings are provided in table 3 for disaster exposure during the perinatal period and childhood, and table 4 for exposure during adulthood.

\section{Exposure to disaster in the perinatal and childhood period}

Of the 24 studies that evaluated perinatal and childhood exposure to disaster, 12 studies evaluated human-made disasters ${ }^{29-35} 404147$ and the remaining 12 evaluated natural disasters ${ }^{1521-28} 383942$ of which 2 were pandemics. ${ }^{38}{ }^{39}$ Most studies $(n=15)$ assessed the disaster as the main exposure of interest. ${ }^{2428-3335} 366^{39-42}$ The remaining studies evaluated stress (eg, maternal stress, disaster-related post-traumatic stress disorder (PTSD), subjective stress, objective hardship), ${ }^{21-25} 2747$ maternal weight and maternal nutrition status, ${ }^{153}$ cognitive appraisal $^{26}$ and coping strategies ${ }^{27}$ 


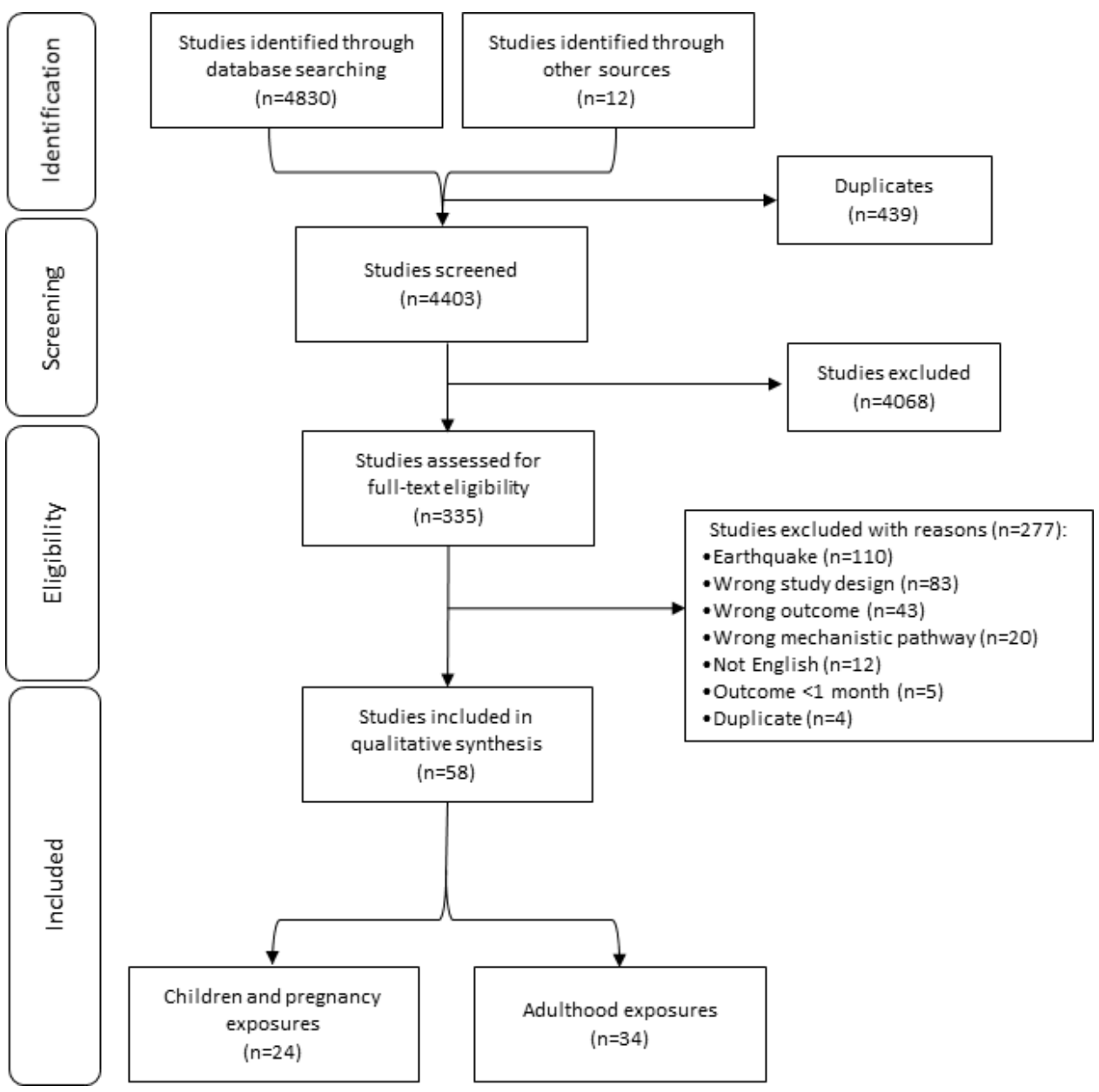

Figure 1 Preferred Reporting Items for Systematic Reviews and Meta-Analyses (PRISMA) flow diagram.

that were the result of the disaster as the exposure variable. The age when cardiometabolic outcomes were assessed varied across studies, with 2 studies evaluating pregnancy outcomes, ${ }^{27} 28$ studies evaluating outcomes among children and youth, ${ }^{15}$ 21-26 474 studies assessed outcomes during young to mid-adulthood ( $>18-40$ years of age) $)^{27} 293637$ and 10 during later adulthood ( $\geq 50$ years of age). $.^{30-35} 38-42$ One study did not specify the exact age, rather evaluated outcomes throughout adulthood, from 18 to 63 years of age.$^{31}$ Detailed characteristics and findings of all studies that assessed perinatal and childhood exposures to disasters can be found in table 3 .

Within the 10 studies that evaluated perinatal or childhood disaster exposure in relation to pregnancy, childhood or youth outcomes, 1 study evaluated a human-made disaster (the World Trade Center attacks) and the other 9 studies evaluated natural disasters (including ice storms, floods and hurricanes) and the findings were mixed. The one study that evaluated a human-made disaster found limited evidence of any increased cardiometabolic risk and a small decrease in both body mass index (BMI), and zBMI was observed for children exposed to the World Trade Center attacks compared with those who were not found no differences in triglycerides or lipids. ${ }^{47}$ Within the eight studies that evaluated exposure to a natural disaster during the perinatal and childhood period and cardiometabolic outcomes in later childhood, there were six studies that evaluated measures of child growth and four of these studies reported increased BMI or adiposity in later childhood, ${ }^{21} 232526$ one study was null, ${ }^{22}$ and one study reported increased wasting or malnutrition following exposure to a flood. ${ }^{15}$ Importantly, the one study where increased wasting was observed was in Bangladesh, whereas all of the studies that observed increased risk of obesity were in North America. Of the studies that evaluated childhood cardiometabolic outcomes other than growth, one study found increased insulin concentrations at age 13 years. ${ }^{24}$ There were two studies that evaluated exposure to a natural disaster (Hurricane Katrina and Hurricane Sandy) during pregnancy and both found increased incidence or hospital visits for gestational hypertension and diabetes. ${ }^{27} 28$

There were 14 studies that evaluated exposure to a disaster in pregnancy or childhood in relation to the subsequent onset of adult cardiometabolic conditions; 11 of these studies evaluated exposure to human-made disasters and 3 evaluated natural disasters. Within the 11 studies that evaluated human-made disasters, 1 study found no association between exposure to the Dutch famine and coronary artery disease in older adulthood. ${ }^{32}$ 
Table 2 Characteristics of included studies $(n=58)$

\begin{tabular}{lc}
\hline Characteristics & N (\%) \\
\hline Continent & \\
North America & $36(62)$ \\
Europe & $13(22)$ \\
Asia & $7(12)$ \\
Africa & $2(3)$
\end{tabular}

Year of publication

$\begin{array}{lc}\text { 2010-2020 } & 44(76) \\ \text { 2000-2009 } & 12(21) \\ \text { 1996-1999 } & 2(3) \\ \text { Study design } & \\ \text { Cohort/longitudinal } & 41(71) \\ \text { Quasi-experimental }^{\star} & 10(17) \\ \text { Cross-sectional }^{\text {Cro }} & 7(12)\end{array}$

Sample size

$\begin{array}{ll}\geq 10000 & 19(33) \\ 1000-<10000 & 10(17) \\ \leq 1000 & 24(41)\end{array}$

Not specified

$5(9)$

$\begin{array}{lc}\text { Exposure life stage } & \\ \text { Pregnancy/childhood } & 24(41) \\ \text { Adulthood } & 34(57) \\ \text { Outcome life stage } & 2(3) \\ \text { Pregnancy } & 8(13) \\ \text { Childhood } † & 47(81) \\ \text { Adult } & \\ \text { Disaster } & 23(40) \\ \text { Human-made } & 35(60) \\ \text { Natural } & \\ \text { Cardiometabolic outcome } \ddagger & 41(71) \\ \text { Cardiovascular disease } \S & 11(19) \\ \text { Diabetes } & 12(21) \\ \text { Obesity or BMl } & 9(16) \\ \text { Mortality from cardiovascular disease } & 2(3) \\ \text { Cardiometabolic risk during pregnancy }{ }^{\star *} & \end{array}$

*Includes pre/post-study design, time-series and natural experiments.

†Children defined as $\leq 18$ years of age.

$\ddagger$ Does not equal to $100 \%$ as studies report multiple cardiometabolic outcomes.

§Includes hypertension, coronary artery disease/heart disease, angina, heart attack/myocardial infarction, metabolic syndrome, cardiac disease-related blood markers, stroke.

qDiabetes, blood glucose, metabolic syndrome.

**Gestational diabetes, gestational hypertension, pre-eclampsia. $\mathrm{BMI}$, body mass index.

While the remaining 10 studies all found some evidence of increased cardiometabolic outcomes in adulthood following perinatal or childhood exposure, the results were mixed with many null results depending on outcome or exposure. For example, prenatal exposure to famine was associated with higher low-density lipoprotein (LDL) and coronary heart disease approximately 28 years later, however no difference was found for glucose, insulin, BMI or other lipids. ${ }^{29}$ The results were not consistent across outcomes, for example, increased risk of hypertension was found in three studies ${ }^{293640}$ but not in two studies. ${ }^{3537}$ Within the three studies that evaluated adult cardiometabolic outcomes following exposure to a natural disaster, all three studies found increased risk of CVDs or mortality following prenatal exposure to famine or the 1918 influenza pandemic. ${ }^{38} 3942$

\section{Studies on adult exposure to disaster and subsequent cardiometabolic outcomes}

Thirty-four studies investigated the effects of exposure to disasters during adulthood on cardiometabolic outcomes. The length of follow-up ranged from 1 month to 13 years. There were 23 studies that examined natural disasters, ${ }^{1444-4648515254-5658-6164-6772-76}$ and 11 studies that examined human-made disasters. ${ }^{43} 49505357626368-71$ Of these studies, onlyoneevaluated theimpactofaninfectiousdisease epidemic ${ }^{66}$ Most studies $(\mathrm{n}=27)$ considered the disaster as the main exposure of interest. ${ }^{1443-46} 48505254-5658-6668$ 71-76 The remaining seven studies assessed disaster-related stress, ${ }^{53} 576769$ including PTSD and psychological strain, unemployment rates as a result of the disaster ${ }^{51}$ and exposure to damaged or collapsed buildings during the World Trade Center disaster. ${ }^{70}$ Detailed characteristics and findings of all studies that assessed adult exposures to disasters are included in table 4.

The studies that assessed exposure to human-made disasters $(n=11)$ during adulthood reported mixed results in terms of associations with outcomes and statistical significance. Three studies assessed PTSD related to disasters and found an increased association with stoke, ${ }^{69}$ heart disease ${ }^{57}$ and cardiovascular/vascular problems, ${ }^{53}$ two of which were exposure to the World Trade Centre disaster and the third was a fireworks depot explosion. Two studies assessing exposure to the World Trade Center disaster and Amsterdam Air disaster found an increased association with cardiovascular hospitalisations ${ }^{49}$ and cardiovascular symptom complaints ${ }^{62}$ in rescue workers compared with non-rescue workers. Of the remaining six studies, three studies reported an increased association with hypertension, ${ }^{43}$ systolic blood pressure ${ }^{71}$ and CVD mortality, ${ }^{63}$ however, the exact exposure varied across studies. For instance, one study explored the level of exposure, defined as low, intermediate or high to the World Trade Center disaster, ${ }^{63}$ whereas another study evaluated exposure to the Volendam Pub fire among parents who had children who were injured or died. ${ }^{43}$ The final three studies assessing exposure to human-made disasters (World Trade Center disaster and Sewol Ferry disaster) reported mixed results with some showing a decreased association or null findings. ${ }^{53} 6870$ 


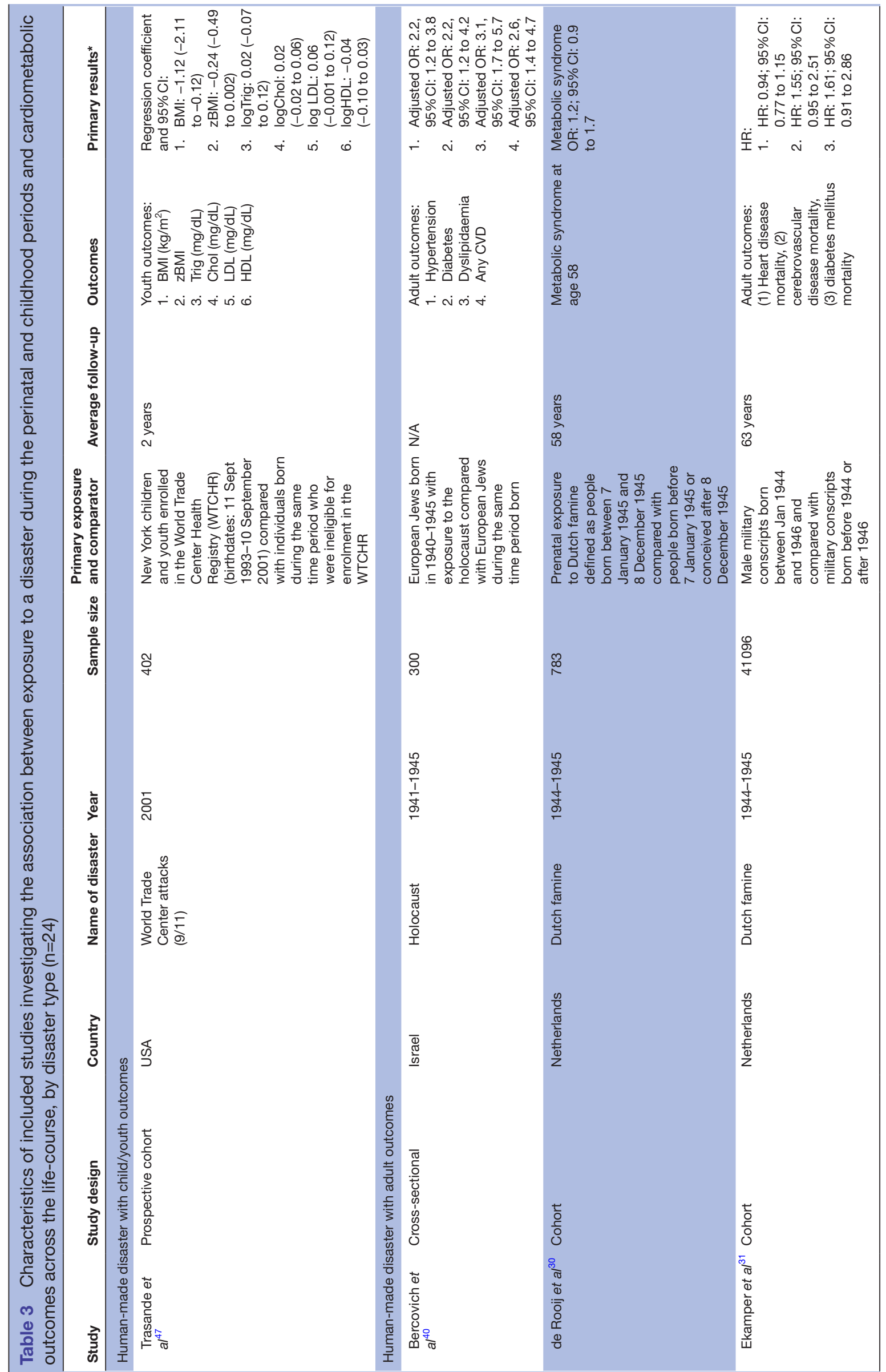




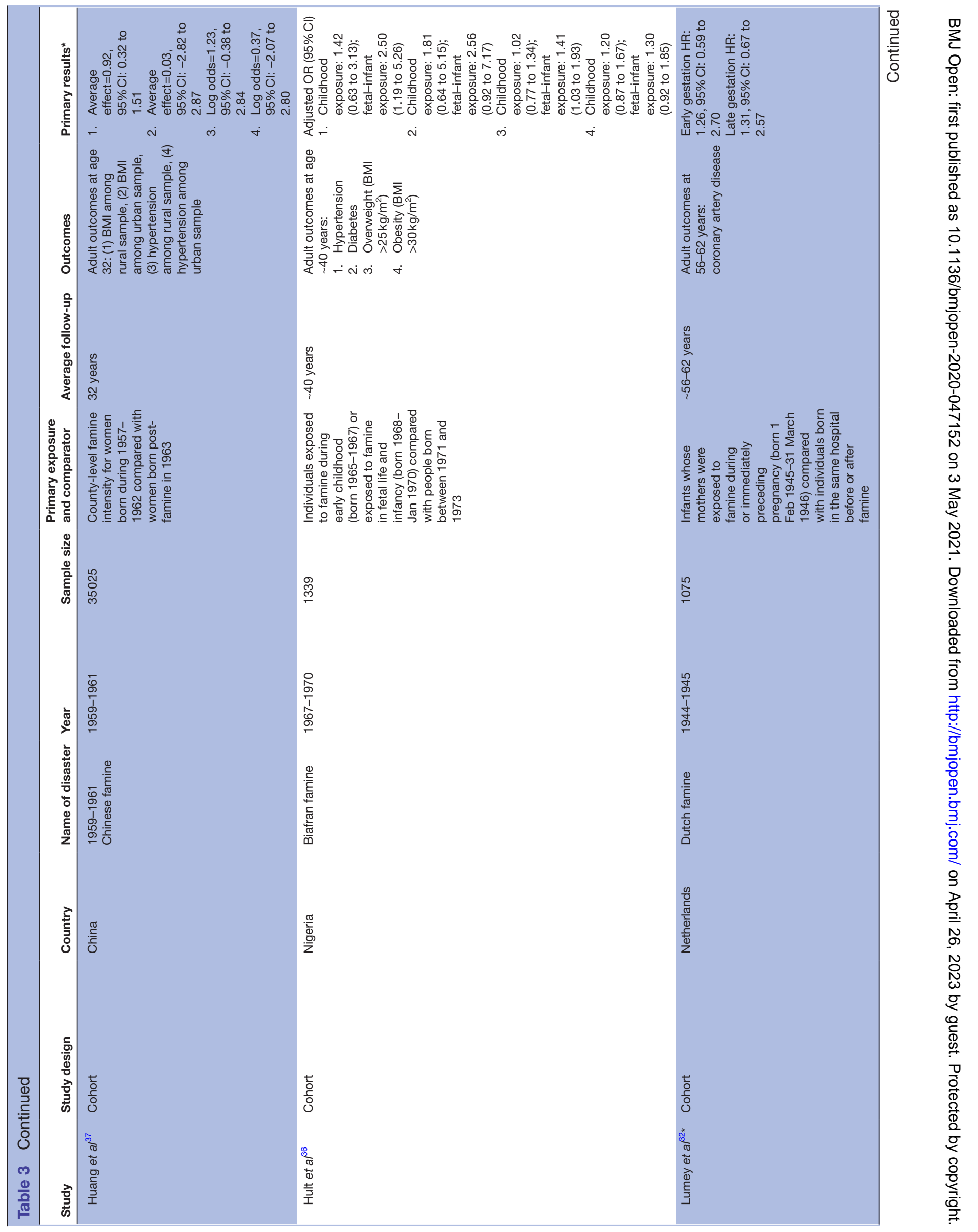




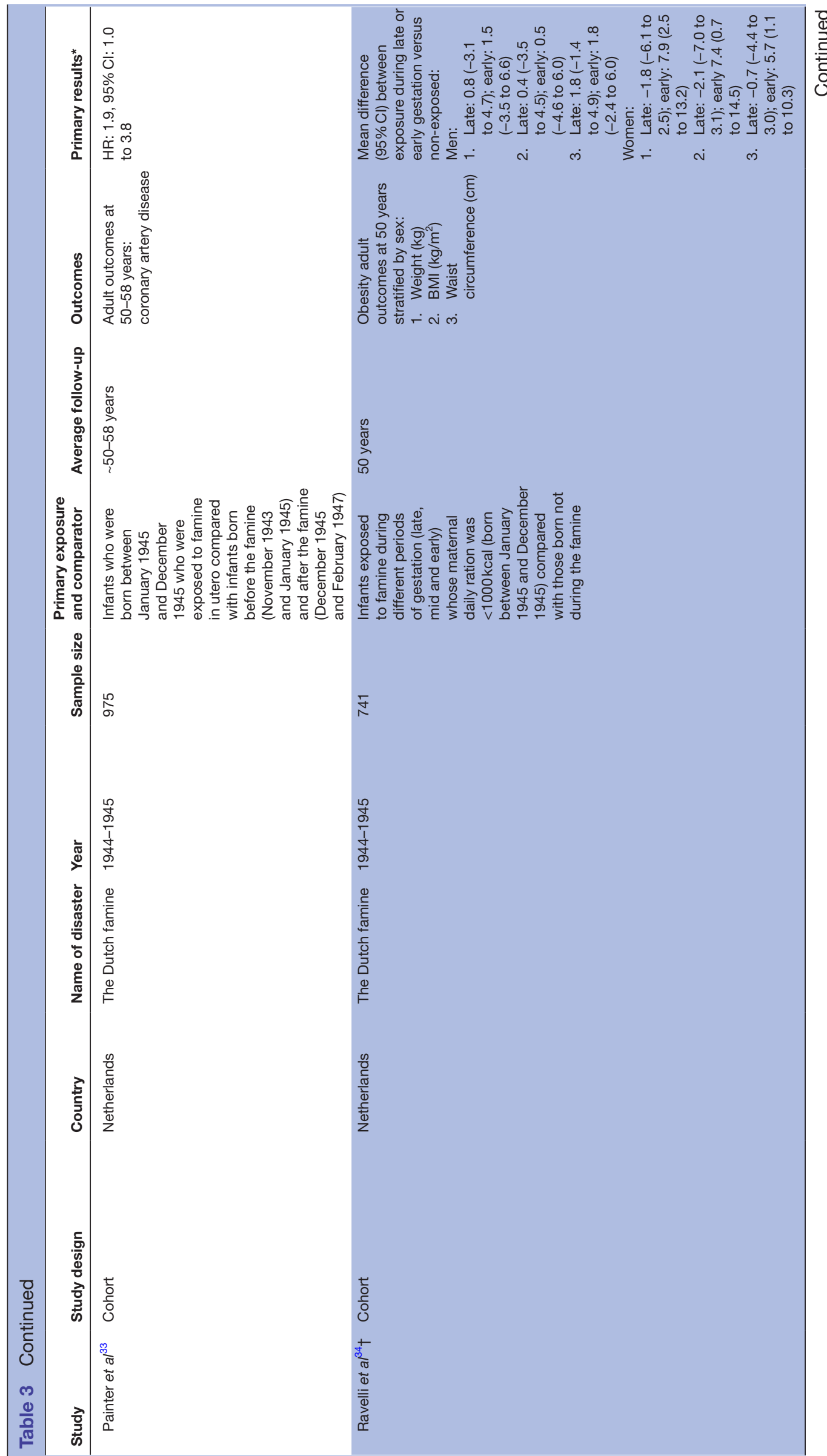

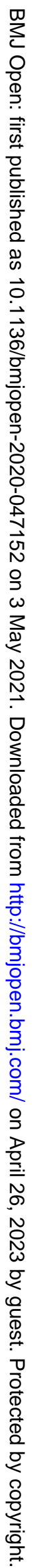




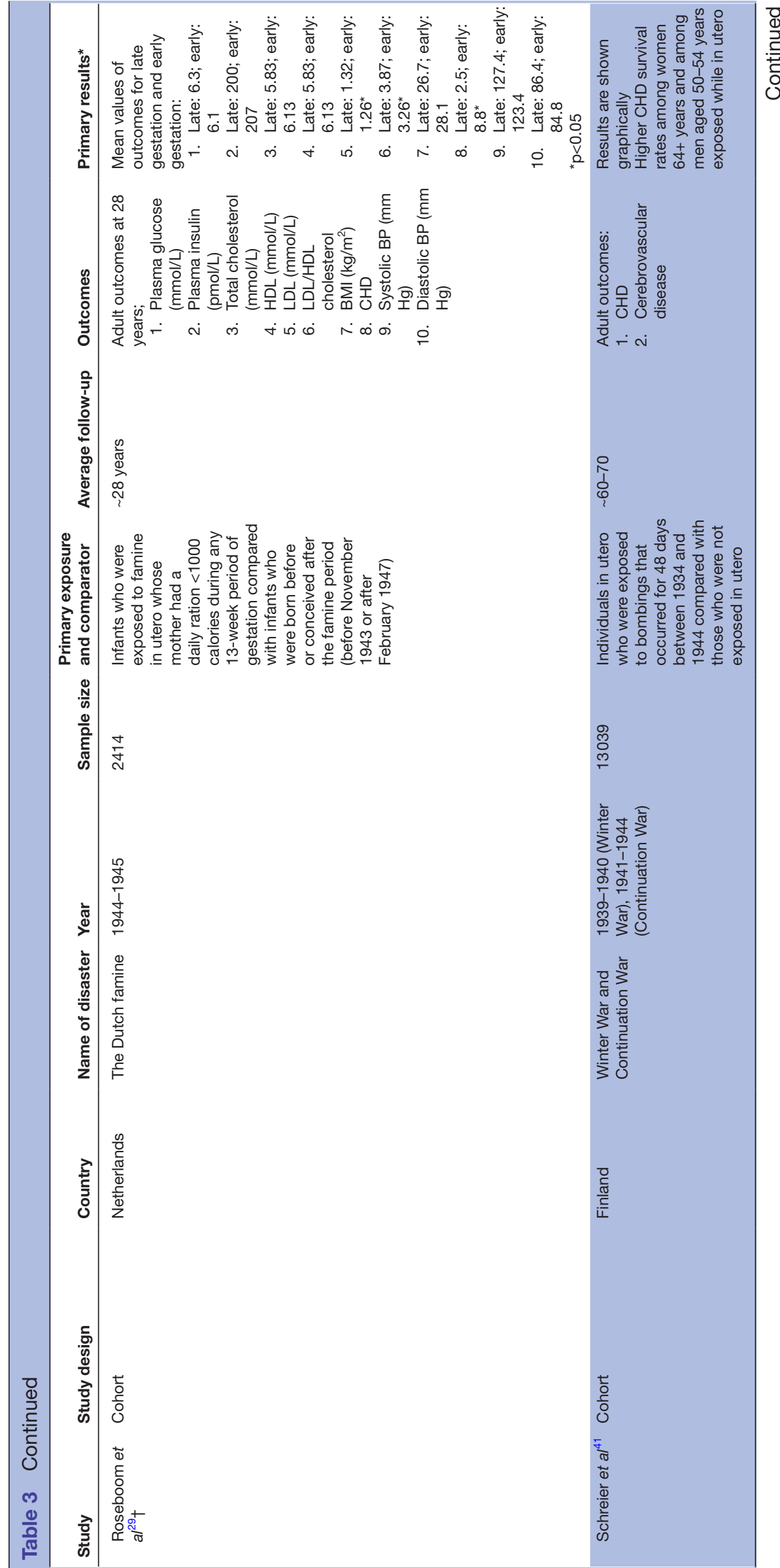




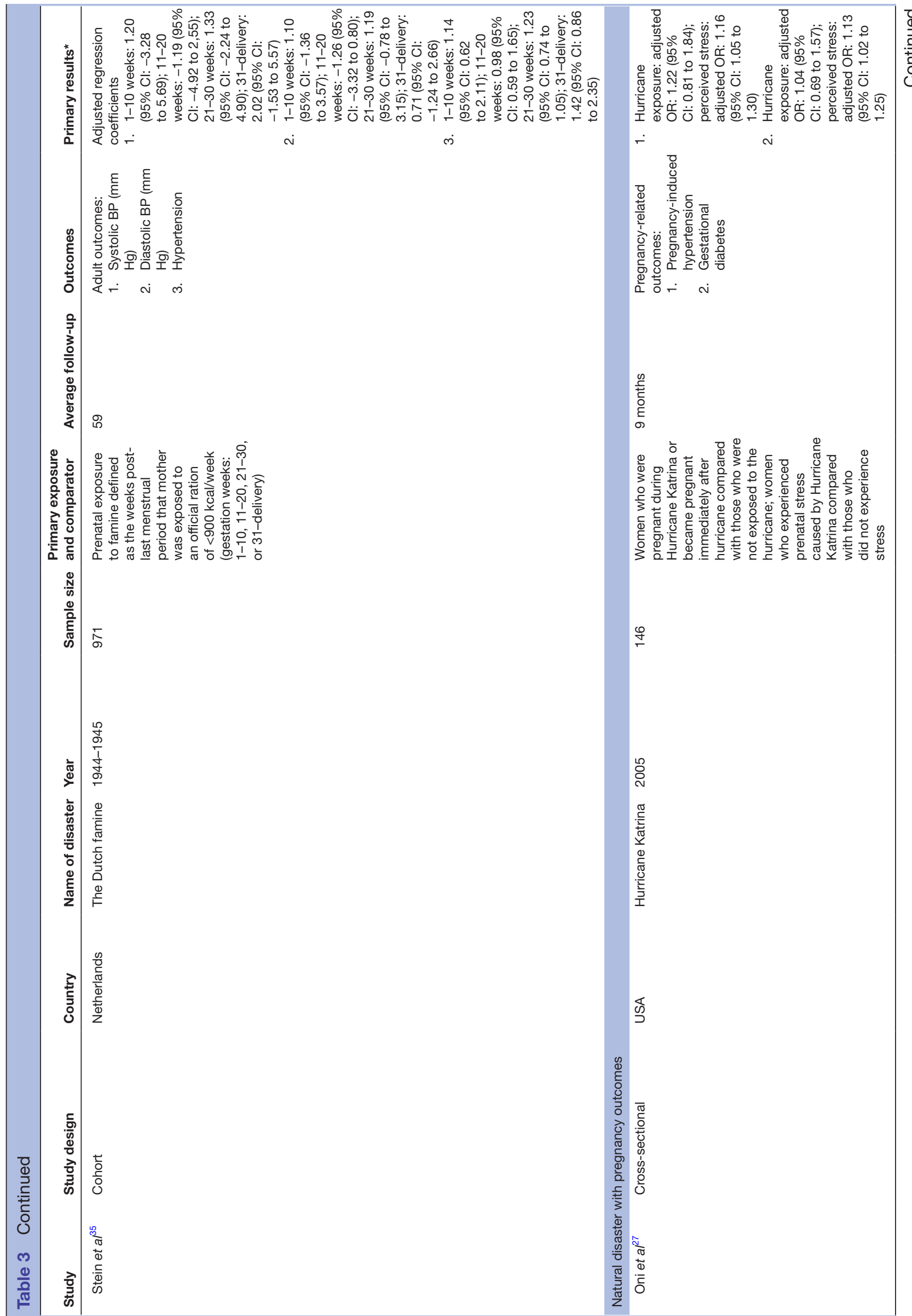




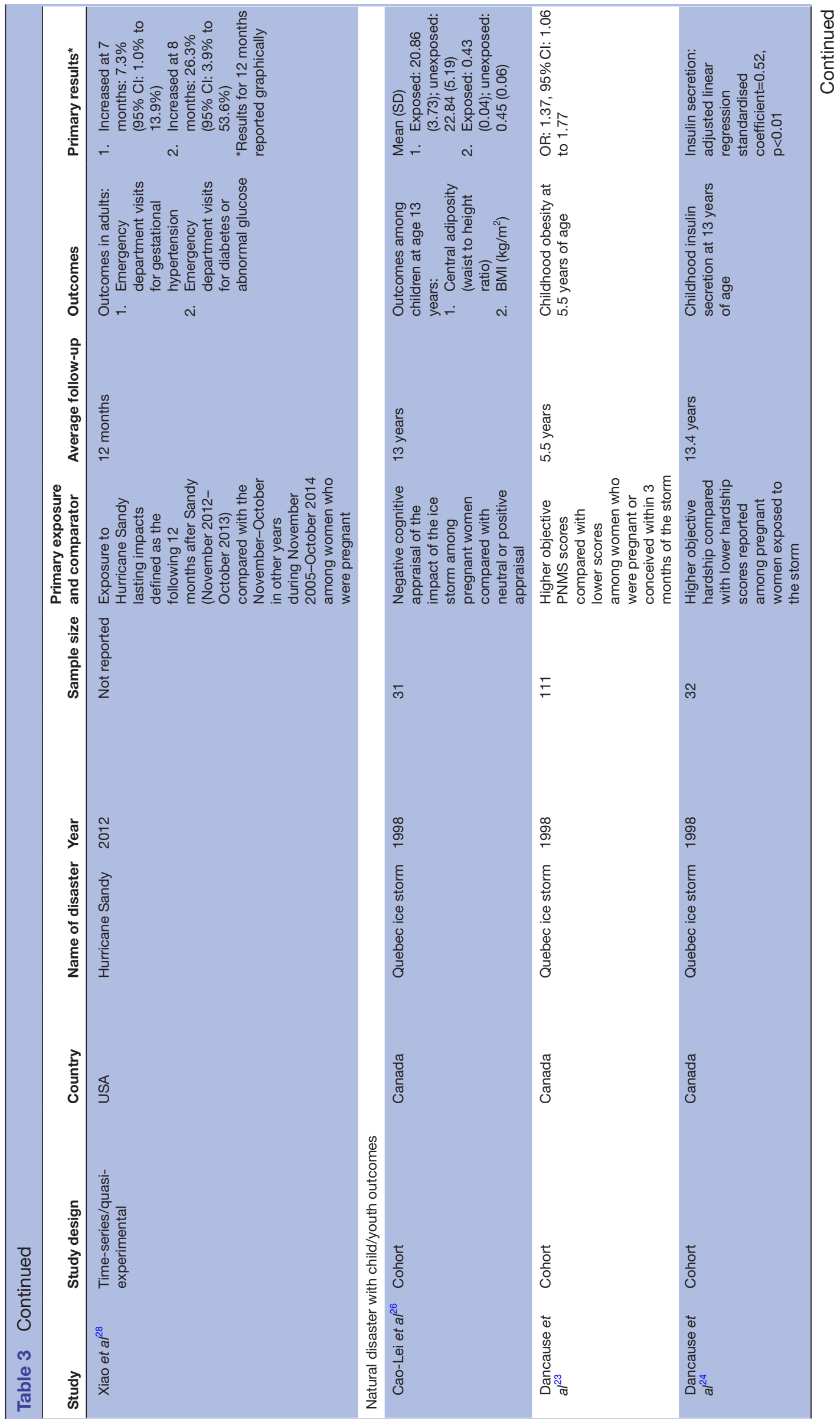

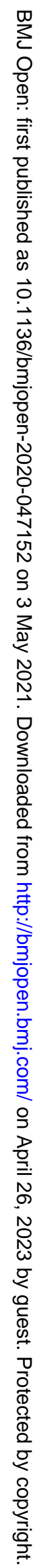




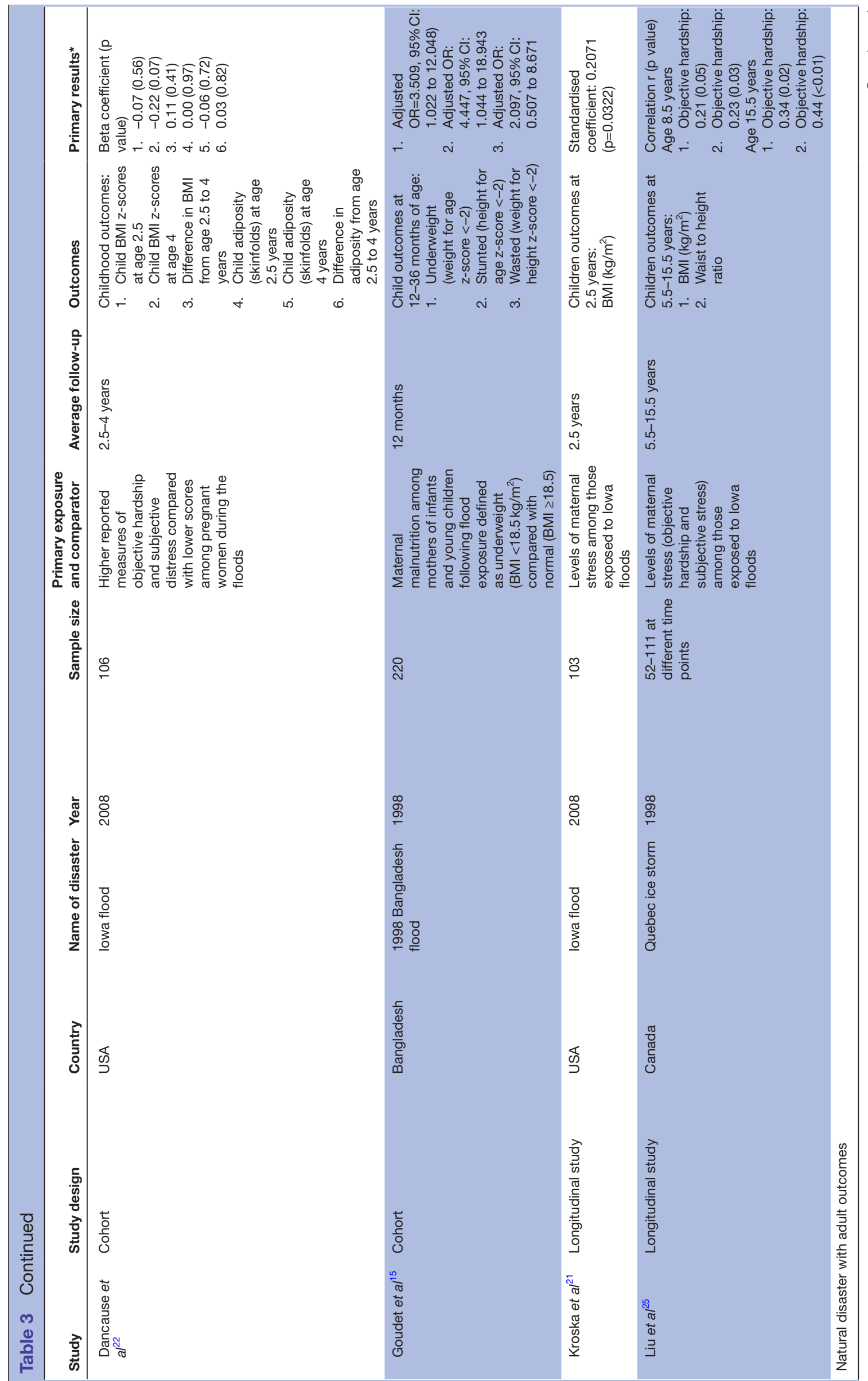

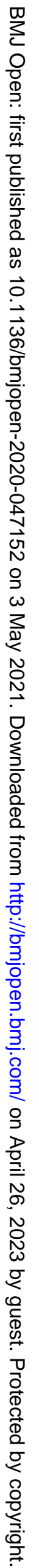




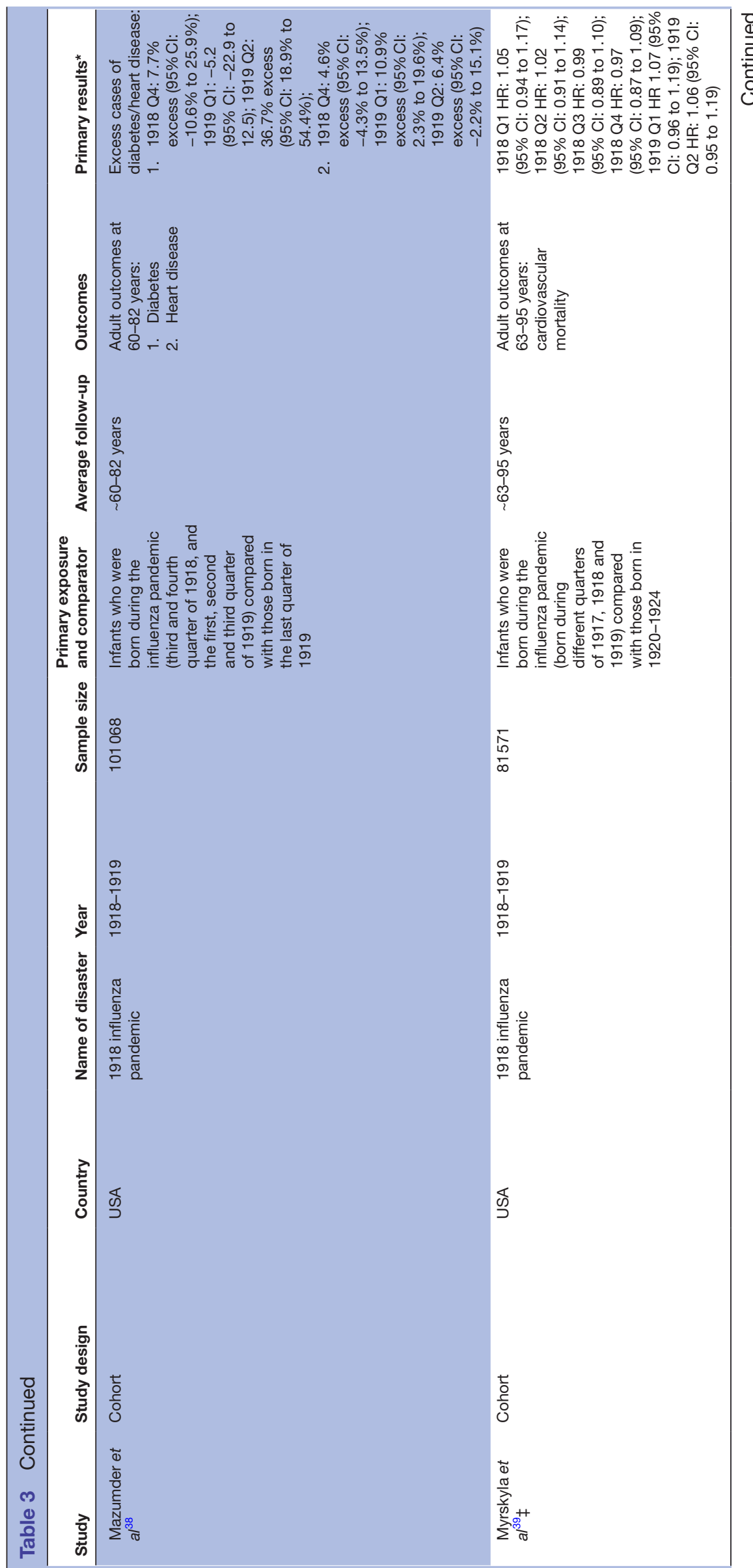

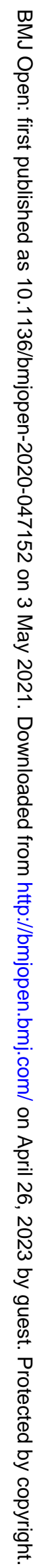




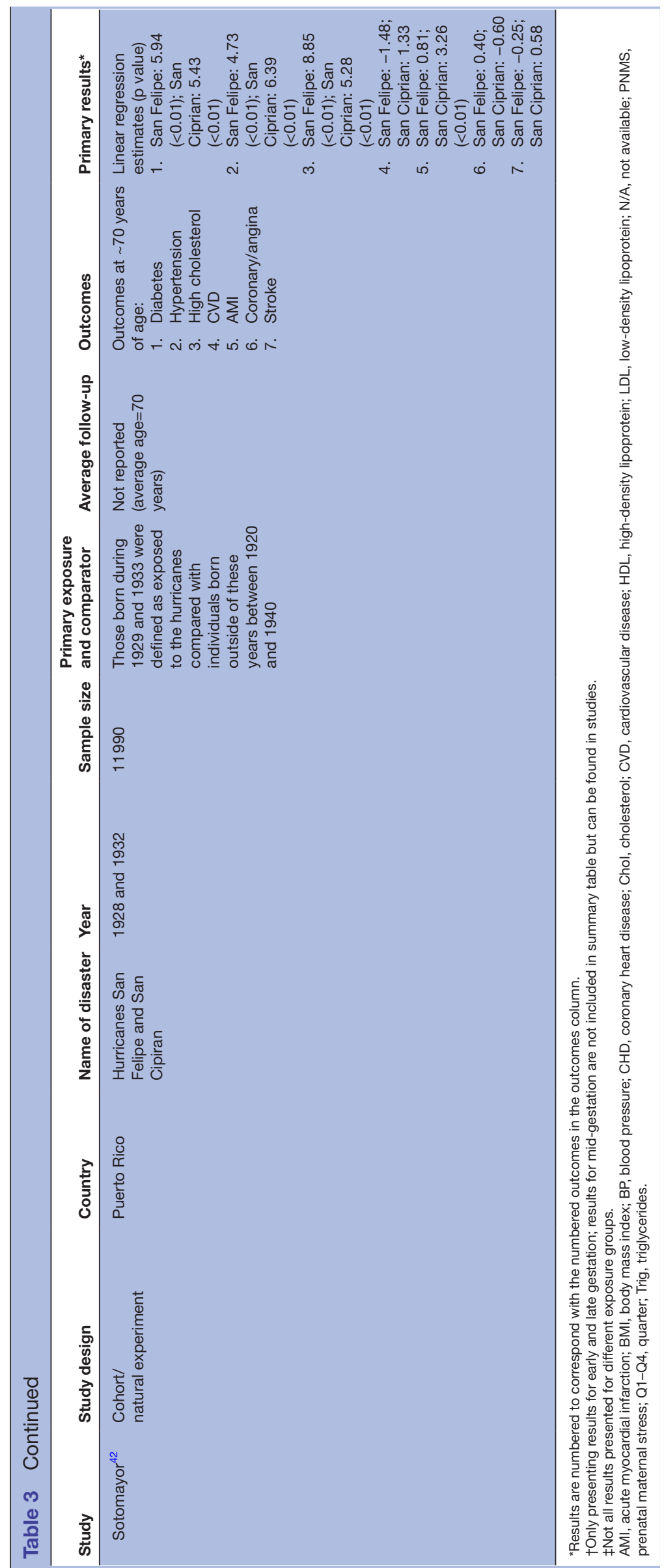

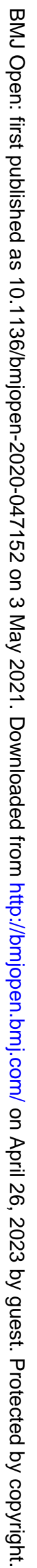




\section{Open access}

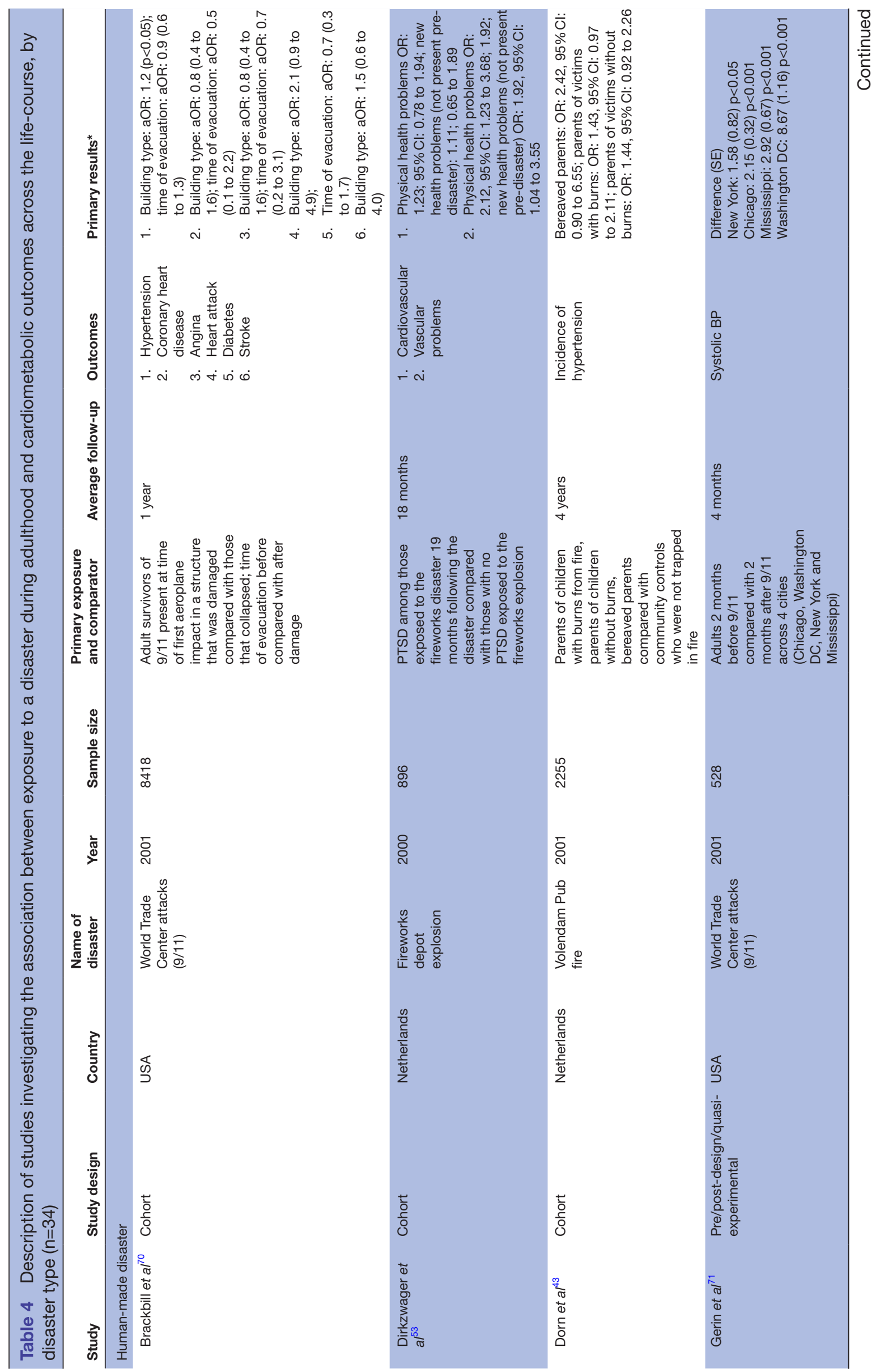

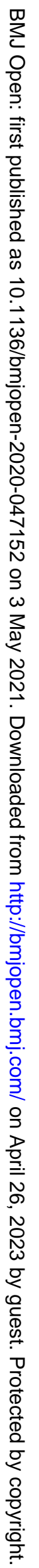




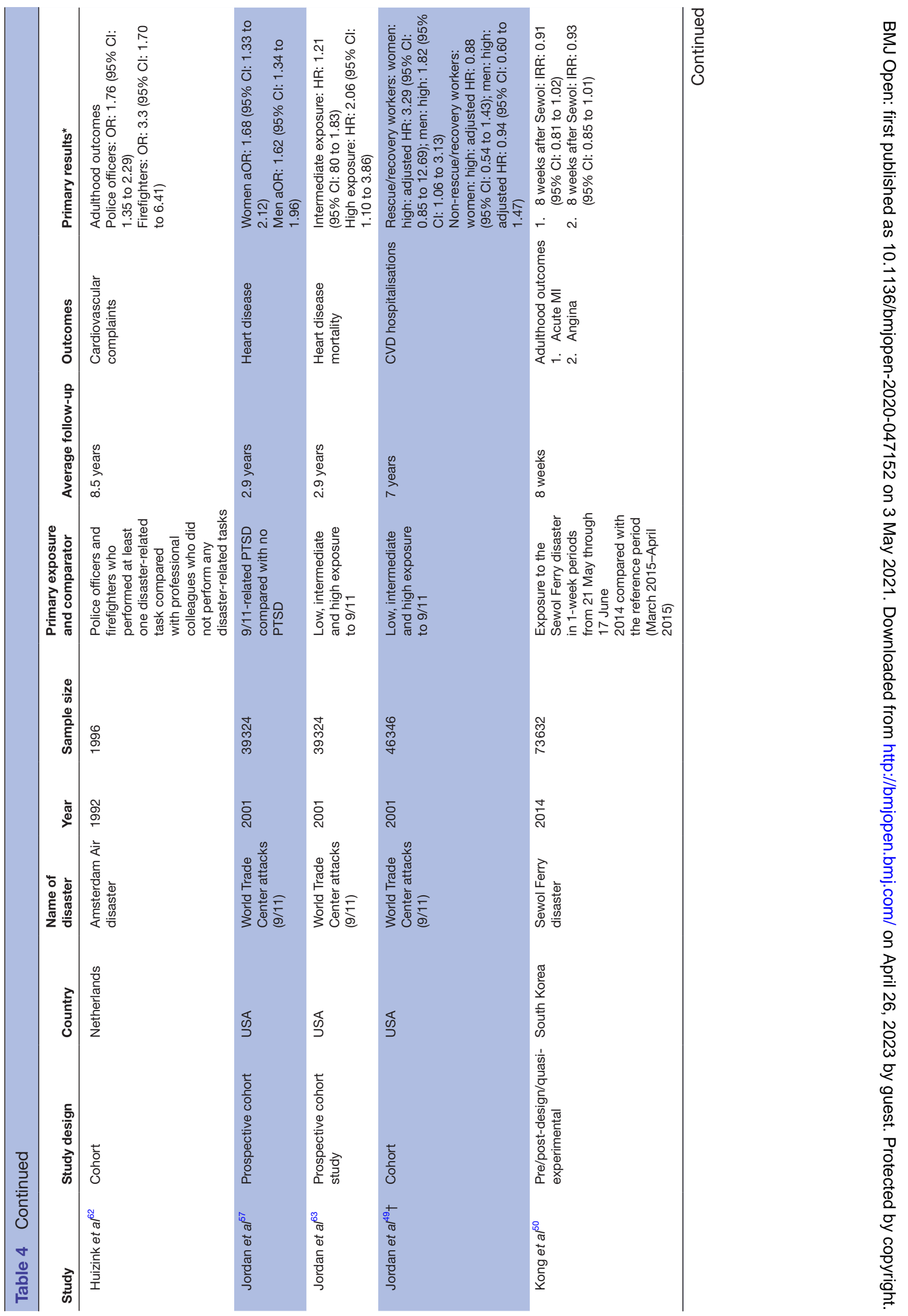




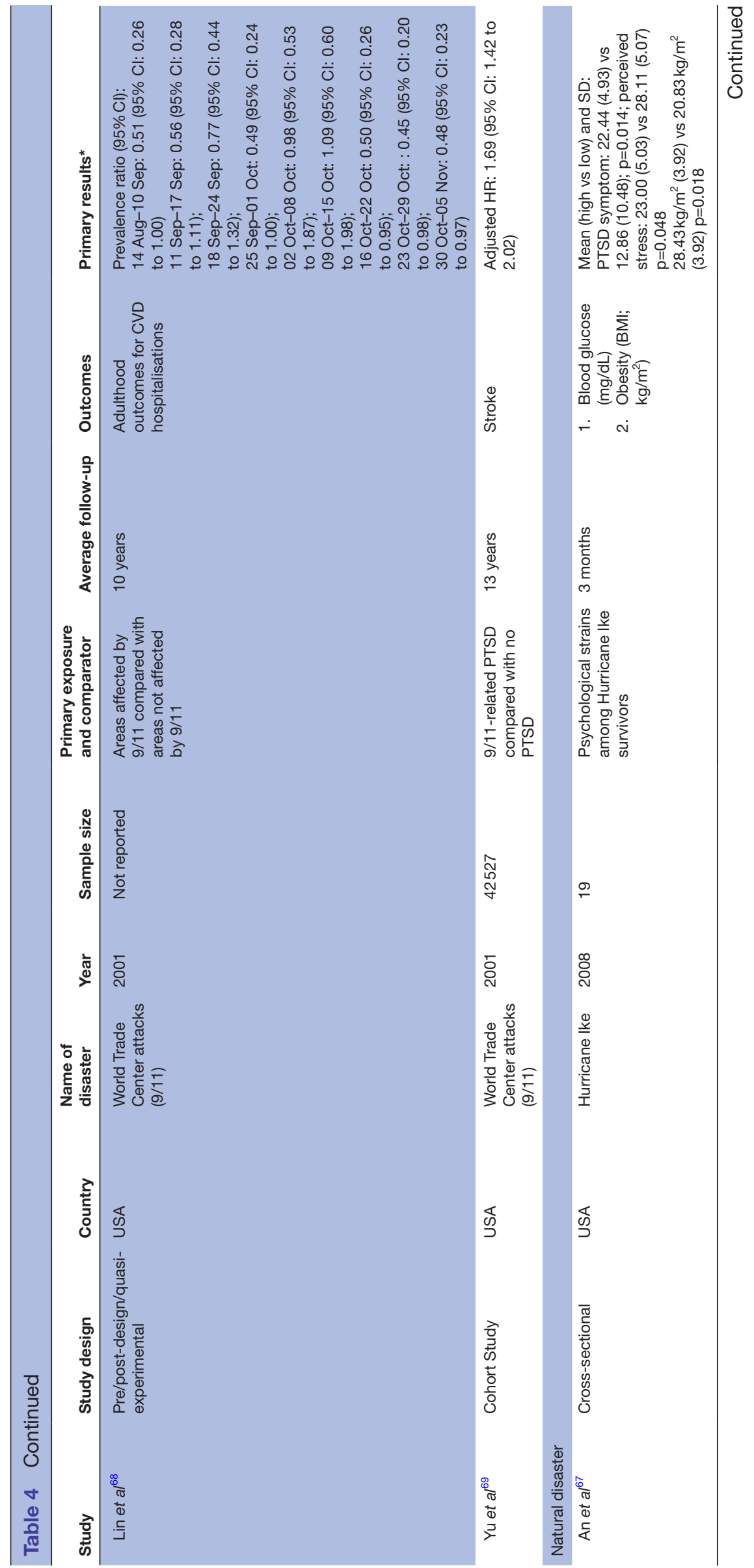




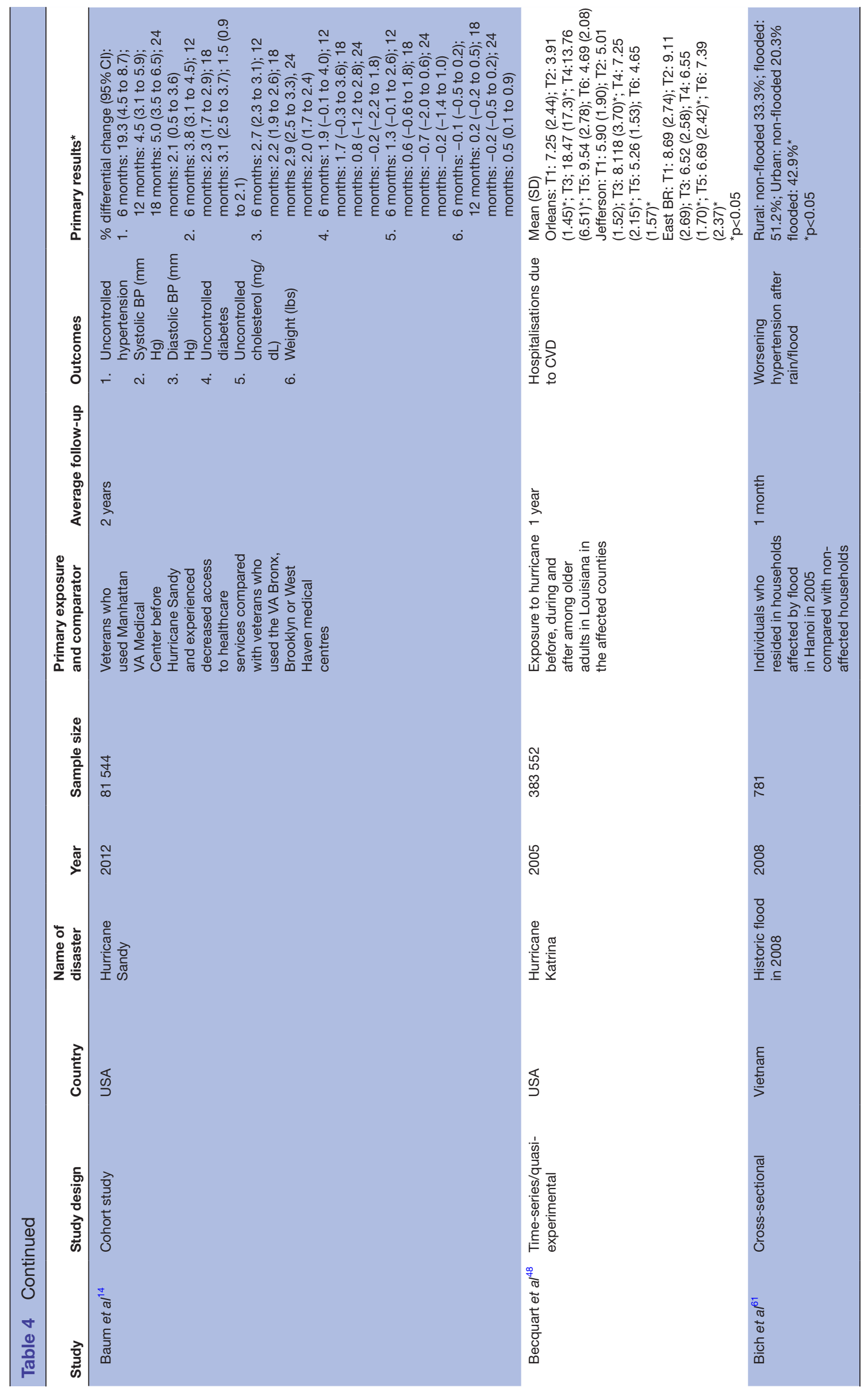




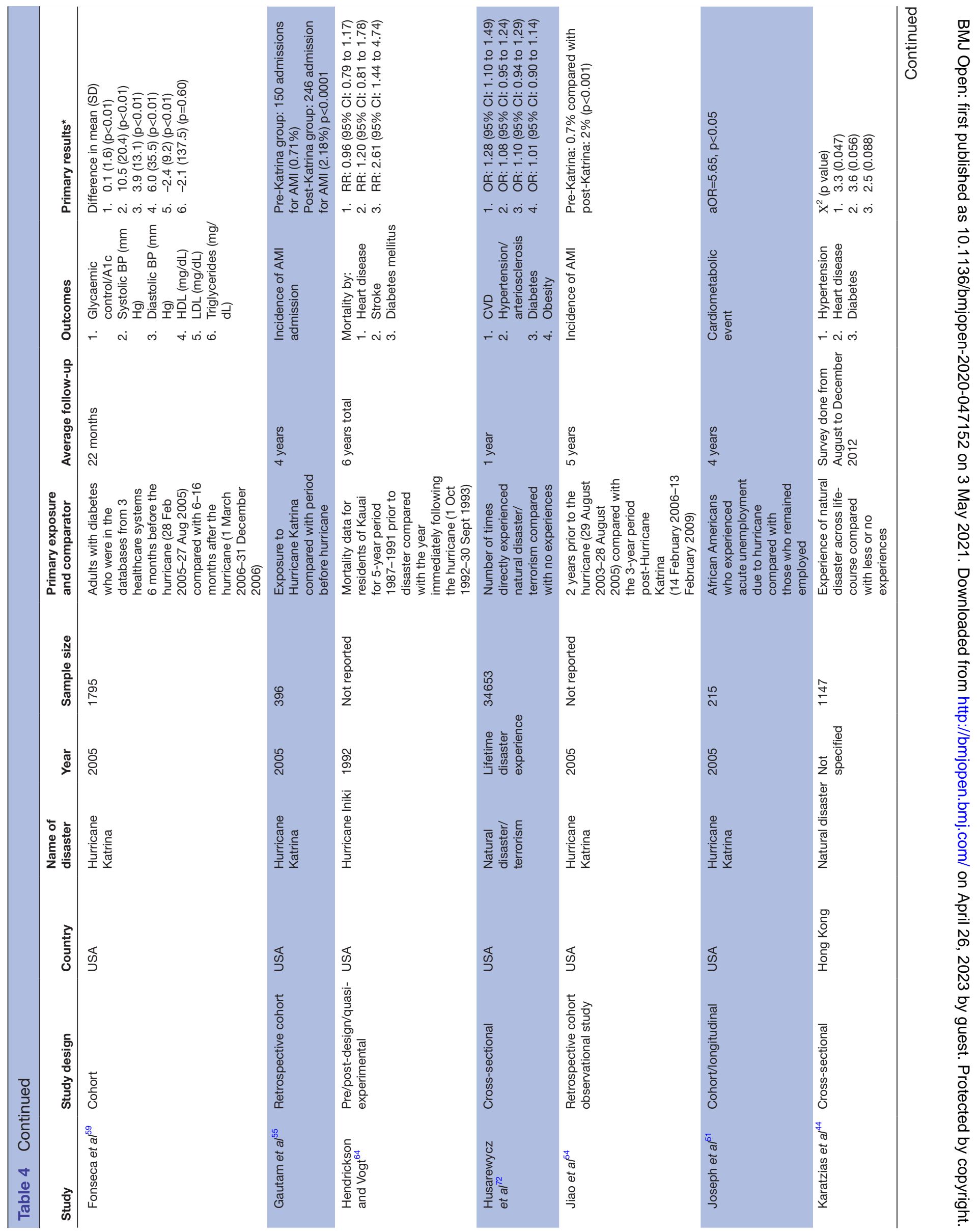




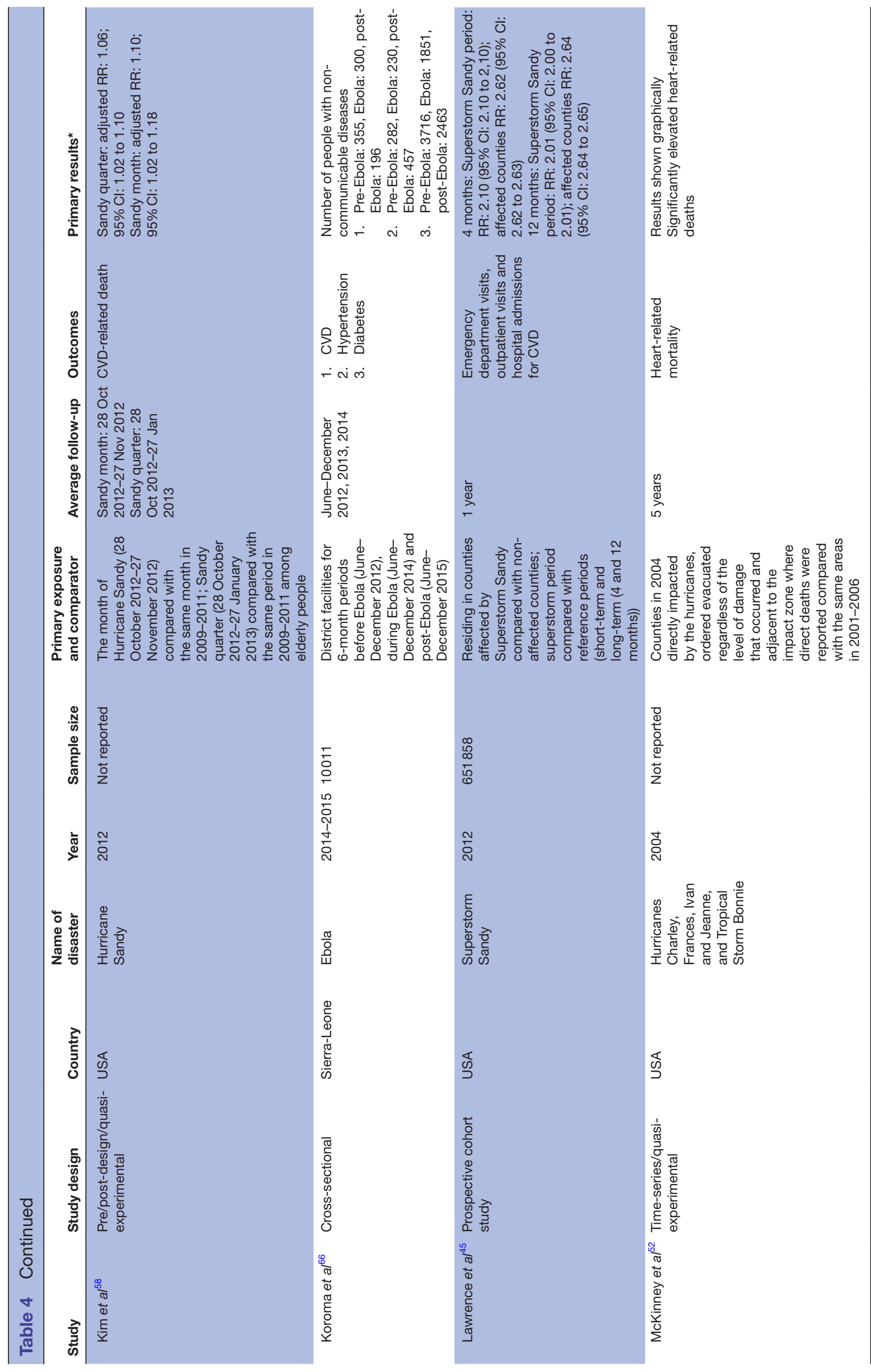

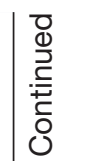




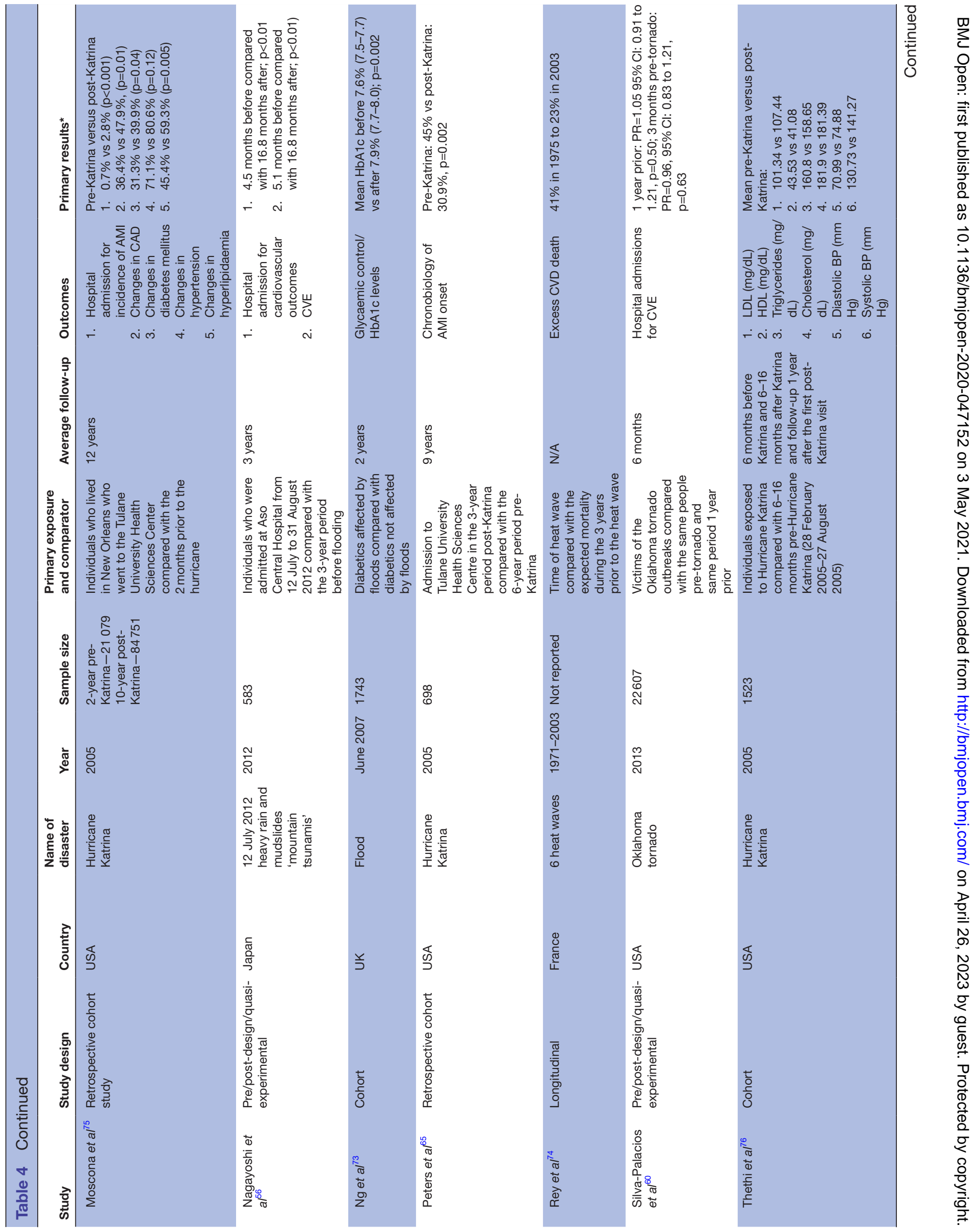




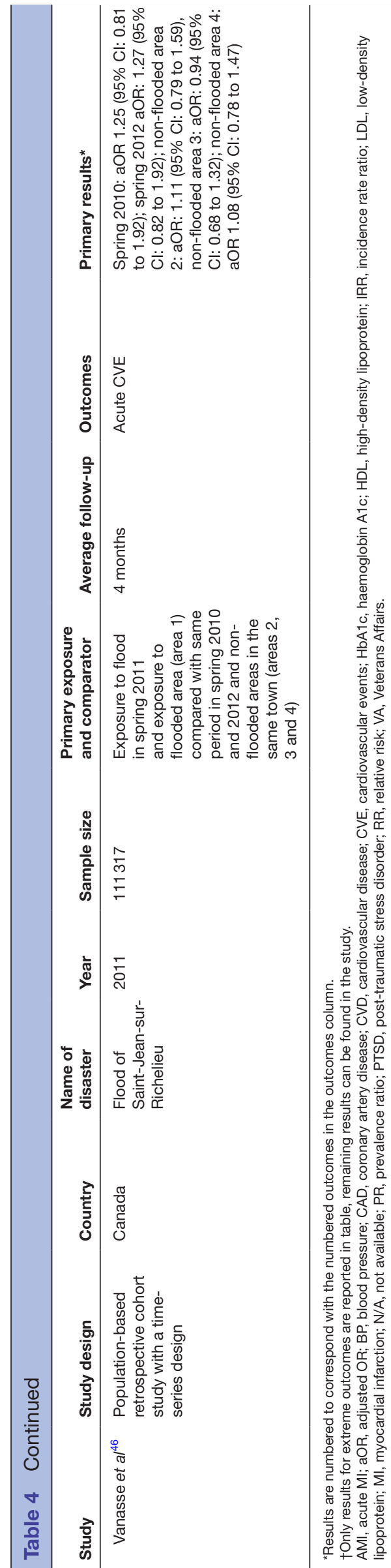

Among studies that evaluated the impact of exposure to natural disasters $(\mathrm{n}=23)$, six studies that evaluated exposure to Hurricanes Sandy, Katrina, Iniki, and the flood of Saint-Jean-sur-Richelieu reported an increased association with cardiometabolic outcomes. ${ }^{45} 4651586472$ One of these studies specifically investigated unemployment as a result of Hurricane Katrina and found those who were unemployed, compared with those who remained employed, were 5.65 times more likely to have a cardiometabolic event $(\mathrm{p}<0.05) .{ }^{51}$ Nine studies reported a statistically significant increase in outcomes following exposure to a disaster..$^{52}$ 54-56 6167 73-75 For instance, one study found those who reported higher levels of psychological strain after surviving Hurricane Ike, compared with those with lower levels of psychological strain, had higher mean blood glucose and obesity 4 months after the disaster. ${ }^{67}$ Whereas, another study found a higher proportion of people experiencing worse hypertension who were living in households affected by the 2008 Hanoi flood compared with those who lived in an unaffected households in both rural and urban areas. ${ }^{61}$ Two of these studies reported an increase in incidence of acute myocardial infarction (AMI) and AMI hospital admission pre-Hurricane Katrina, compared with post-Hurricane Katrina. ${ }^{54} 55$ Three studies found varying associations across outcomes reported within their study. For example, Fonseca $e t a l^{\tilde{9}}$ found an increased mean difference pre/post-Hurricane Katrina for glycaemic control, systolic blood pressure, diastolic blood pressure and high-density lipoprotein, but not for LDL and triglycerides. Nine studies reported mixed findings across outcomes within the study. Four of these studies found both an increase and decrease in outcomes when comparing mean difference or proportion pre/post-disaster. ${ }^{1446676}$ One study found those with higher reports of exposure to natural disaster throughout the life-course were significantly different from those with lower reports. ${ }^{44}$ The final two studies found a decreased proportion of AMI following Hurricane Katrina ${ }^{65}$ and no significant association between exposure to the Oklahoma tornado and hospital admission for cardiovascular events. ${ }^{60}$

\section{Mediation and modification of cardiometabolic outcomes}

Across all studies, few evaluated effect modification or subgroups of a population that may be at a greater risk of negative health outcomes following disasters. Eight studies stratified by sex, ${ }^{30} 34364145505764$ gestational timing of exposure, ${ }^{22} 2931-333538$ year of birth or age at outcome, ${ }^{426469}$ urban or rural area, ${ }^{37}$ race ${ }^{45} 48$ and socioeconomic status, ${ }^{67}$ however, results varied greatly due to the differences in exposure period, disaster type, cardiometabolic outcome and age at outcome. One study explored the possible mediators between cognitive appraisal following the Quebec ice storm and obesity. It was noted that negative cognitive appraisal was found to predict obesity via DNA methylation of diabetes-related genes. ${ }^{26}$ No studies evaluated or discussed possible 
interventions to mitigate risk of cardiometabolic disease following a disaster.

\section{Critical appraisal}

The critical appraisal assessment for all study designs can be found in the online supplemental tables A2-A4. Among the cohort studies, most studies met all criteria included in the checklist indicating high study quality. For instance, almost all cohort studies had comparable populations that were recruited in a similar way and exposures that were assessed in the same way across populations. However, across almost all cohort studies, information on follow-up or strategies to address incomplete follow-up were unclear or not addressed. The critical appraisal results for cross-sectional studies were inconsistent with a small number of studies meeting only some checklist requirements. For quasi-experimental studies, the checklist requirements for within-person comparisons were not applicable for all studies, however, all studies clearly defined the cause and effect within the study.

\section{DISCUSSION}

\section{Principal findings}

A total of 58 studies were identified and they covered a wide breadth of exposures to both natural and humanmade disasters, including famine, war, terrorism, natural disasters and infectious disease epidemics. Exposures were investigated in pregnancy and childhood exposure through to adulthood with outcomes measured 1 month to 95 years later. The reviewed studies reflect a true lifecourse body of literature with exposures at multiple ages and long-term exposures. A range of cardiometabolic outcomes including obesity, hypertension, myocardial infarction, diabetes and cardiac mortality were investigated. Given the varied nature of the studies, it was difficult to draw overall conclusions, but the vast majority of studies provided some evidence of increased cardiometabolic risk following disaster exposure. There were only 11 studies that reported no increased risk or had unclear findings. Across these studies, there was a variety of disaster exposure, outcomes and follow-up periods, however, seven of these studies did not report adjustment or consideration of any confounders.

\section{Relation to other studies}

To the best of our knowledge, this is the first review to systematically review the literature on a broad range of disasters and cardiometabolic health outcomes across the life-course. Other reviews have focused on a specific population, such as older adults, specific disaster types (eg, natural disasters only) or other health conditions (eg, mental health) or acute outcomes. ${ }^{568}$ However, across most reviews it was apparent the heterogeneous nature of included studies makes it difficult to summarise findings and make overall conclusions and recommendations. For instance, Chan and Sondorp ${ }^{8}$ found exposure to natural disasters negatively affected those with chronic conditions, although authors noted limitations due to limited literature. Another systematic review found very heterogeneous results when reviewing the literature on health outcomes after disasters for older adults with chronic disease. ${ }^{5}$ The studies included here were from multiple disciplines, used a variety of study designs, assessed several different outcomes and applied different statistical approaches. Overall, the results suggested increased risk of adverse cardiometabolic outcomes following disasters, although this was not apparent across all included studies. ${ }^{6}$ The unexpected nature of disasters, uniqueness of population or region affected, and scale of damage lead to research studies that vary greatly. Although previous reviews and the current review have identified quite heterogeneous studies, overall conclusions suggest risk of disease increases after exposure to disasters.

\section{Biological mechanisms}

Several potential mechanisms were discussed in the included studies that may contribute to the observed associations between disaster exposure and increased cardiometabolic outcomes, include the role of both objective and subjective stress, nutritional changes, and reduced access to healthcare. One study that explored mediators in the association between stress and obesity measures identified the role of DNA methylation in this association. ${ }^{26}$ It is well postulated that the activation of a stress response following a stressful event leads to changes in the nervous, cardiovascular, endocrine and immune systems. ${ }^{77}$ Exposure to disasters including famine, war, terrorism, natural disasters and infectious disease epidemics may activate a stress response, altering the progression of disease development. ${ }^{77}$ The repeated or prolonged exposure to various disasters, such as a pandemic spanning over months, may lead to worse health outcomes. Reduction in health services is another possible mechanism leading to worse health outcomes. Healthcare services may be directed toward the immediate response to health-related consequences caused by the disaster (eg, illness from a pandemic, injuries associated with a terrorist attack or natural disaster), limiting access to primary care. ${ }^{78}$ This interruption to services may decrease screening or early treatment ultimately leading to the rise in chronic diseases. Lastly, social determinants of health are known to be important risk factors for cardiometabolic conditions. ${ }^{79}$ At least one study investigated whether the observed associations were due to changes in educational attainment ${ }^{42}$ and unemployment. ${ }^{51}$ More investigation of the role of social determinants as modifiers or mediators of the associations between disasters and long-term cardiometabolic outcomes may be warranted. Despite numerous proposed biological mechanisms and well-established life-course frameworks, relatively few studies actually evaluated potential causal pathways using a life-course framework, and this may contribute to some of the observed heterogeneity in results. 


\section{Strengths and limitations}

This review had several strengths including the comprehensive evaluation of the impact of a wide range of disaster exposures on various cardiometabolic outcomes at different periods throughout the life-course. The search strategy was developed in consultation with health science librarians at McMaster University to ensure the most comprehensive search was developed and relevant literature was identified. The timely findings of this synthesis are a strength of this review, given the current COVID-19 pandemic, which is affecting millions of people worldwide. While only a small proportion of the identified studies focused on pandemics and epidemics, the findings may serve to guide our understanding of expected outcomes, and to develop future research to study the effects of COVID-19 on cardiometabolic outcomes.

Although this review had several strengths, interpretation of findings should be done with caution due to limitations. First, the heterogeneity across studies restricted the ability to conduct a meta-analysis. Studies varied in terms of study design, reported measures of effect, the comparison group (eg, some studies did not include a comparator group), length of follow-up, timing and measurement of exposure, and primary outcomes and how they were measured. Given the multidisciplinary nature of the identified studies, a wide range of analytical approaches were used, and measures of effect varied. These differences in addition to the lack of statistical significance across studies make it difficult to draw overall conclusions. Many of the studies used a retrospective cohort study design and relied on administrative data sources as such many studies were unable to comprehensively adjust for confounders, including social determinants of health. Measurement error and misclassification of exposure status are also possible since many studies did not objectively measure disaster exposure or degree of impact, and instead used proxy measures of disaster exposure based on time and geography.

Very few studies have evaluated the long-term impacts of pandemics and epidemics on cardiometabolic outcomes, identifying a current gap in the literature. This made it difficult to truly assess if exposure to disasters at sensitive periods of development had lasting effects much later in life. Studies also reported insufficient data on subgroups that were at increased risk of worse cardiometabolic health outcomes and interventions that were implemented to mitigate risk of cardiometabolic outcomes. In addition, results were not often explored by sex and gender, or did not apply an equity lens. It has been noted that those of different levels of socioeconomic status experience differential cardiometabolic outcomes. ${ }^{80} 81$ This signifies the importance of exploring associations between exposure to disasters and cardiometabolic outcomes stratified by these factors. Understanding how these associations differ will also help to identify groups of people who will experience worse outcomes following a disaster.

\section{Study implications}

To the best of our knowledge, this is the first study to comprehensively explore the impact of several different types of disasters on cardiometabolic outcomes at different periods throughout the life-course. The results suggest that increased risk is observed for disaster exposure at any period over the life-course from the perinatal child and adult periods. These findings emphasise that the burden of disasters extends beyond the known direct harms they cause, and attention is needed on the detrimental indirect long-term effects on cardiometabolic health and chronic disease. Given the current COVID-19 pandemic, this review may be helpful in raising awareness of the potential increase in cardiometabolic health outcomes post-pandemic, to ensure appropriate public health mitigation measures are developed and implemented to prevent long-term cardiometabolic outcomes at the population level.

\section{Unanswered questions and future research}

Future research should evaluate the impact of pandemics, such as COVID-19, on future cardiometabolic health throughout the life-course. It may also be of interest for future research to explore the impact of implementing public health measures, such as physical distancing to reduce transmission of a virus, and the implications following a disaster with access to healthcare on health outcomes. This information would be helpful in planning public health responses to different disasters. In addition, further investigation of possible mechanisms, such as disruptions to healthcare or medication access, and changes in dietary intake or physical activity, is needed. This would help to develop preventative strategies targeted at these mechanisms to help reduce the possible cardiometabolic consequences after experiencing a disaster. This review found insufficient evidence identifying subgroups of the population who are at the greatest risk or specific disaster-related risk factors that increase cardiometabolic disease development following a pandemic. This is an important gap that needs to be addressed by future research.

\section{Author affiliations}

${ }^{1}$ Department of Health Research Methods, Evidence and Impact, McMaster University, Hamilton, Ontario, Canada

${ }^{2}$ Michael G DeGroote School of Medicine, McMaster University, Hamilton, Ontario, Canada

${ }^{3}$ National Collaborating Centre for Methods and Tools, McMaster University, Hamilton, Ontario, Canada

${ }^{4}$ Centre for Health Economics and Policy Analysis, McMaster University, Hamilton, Ontario, Canada

Twitter Alessandra T Andreacchi @Andreacchi_A and Sarah E Neil-Sztramko @ sarah_ns_phd

Contributors Conceptualisation-VDR, SEN-S, EIA, EmA and LNA. ScreeningVDR, JL, MSA, YY-M, ATA, ES, SI, JDM and RR. Data extraction-VDR, JL, MSA, YY-M, ATA, RR and ES. Critical appraisal—VDR, JL, MSA, YY-M, ATA, ES and SI. Writing (original draft)—VDR, JL and MSA. Writing (review and editing)—VDR, JL, MSA, YY-M, ATA, ES, SI, JDM, RR. SEN-S, EIA, EmA and LNA.

Funding The authors have not declared a specific grant for this research from any funding agency in the public, commercial or not-for-profit sectors. 
Competing interests None declared.

Patient consent for publication Not required.

Provenance and peer review Not commissioned; externally peer reviewed.

Data availability statement All data relevant to the study are included in the article or uploaded as supplemental information. This study was a systematic review, and all data are included in the presented tables.

Supplemental material This content has been supplied by the author(s). It has not been vetted by BMJ Publishing Group Limited (BMJ) and may not have been peer-reviewed. Any opinions or recommendations discussed are solely those of the author(s) and are not endorsed by BMJ. BMJ disclaims all liability and responsibility arising from any reliance placed on the content. Where the content includes any translated material, BMJ does not warrant the accuracy and reliability of the translations (including but not limited to local regulations, clinical guidelines, terminology, drug names and drug dosages), and is not responsible for any error and/or omissions arising from translation and adaptation or otherwise.

Open access This is an open access article distributed in accordance with the Creative Commons Attribution Non Commercial (CC BY-NC 4.0) license, which permits others to distribute, remix, adapt, build upon this work non-commercially, and license their derivative works on different terms, provided the original work is properly cited, appropriate credit is given, any changes made indicated, and the use is non-commercial. See: http://creativecommons.org/licenses/by-nc/4.0/.

\section{ORCID iDs}

Vanessa De Rubeis http://orcid.org/0000-0002-6756-1887

Alessandra T Andreacchi http://orcid.org/0000-0001-6923-9245

Sarah E Neil-Sztramko http://orcid.org/0000-0002-9600-3403

Elizabeth Alvarez http://orcid.org/0000-0003-2333-0144

Laura N Anderson http://orcid.org/0000-0002-6106-5073

\section{REFERENCES}

1 World Health Organization. WHO | Definitions: emergencies [Internet] WHO. World Health Organization, 2020. Available: https://www.who. int/hac/about/definitions/en/

2 Mohamed Shaluf I, Mohamed SI. An overview on disasters. Disaster Prev Manag 2007;16:687-703.

3 Giorgadze T, Maisuradze I, Japaridze A, et al. Disasters and their consequences for public health. Georgian Med News 2011;194:59-63.

4 Ordway D-M. February 1 JR, 2016. Global trends in human infectious disease: Rising number of outbreaks, fewer per-capita cases. Journalist's Resource, 2016. Available: https://journalistsresource. org/studies/society/public-health/global-rise-human-infectiousdisease-outbreaks/

5 Brooks SK, Webster RK, Smith LE, et al. The psychological impact of quarantine and how to reduce it: rapid review of the evidence. The Lancet 2020;395:912-20.

6 Bell SA, Horowitz J, Iwashyna TJ. Health outcomes after disaster for older adults with chronic disease: a systematic review. Gerontologist 2020;60:e535-47.

7 Jackson JL, George S, Hinchey S. Medically unexplained physical symptoms. J Gen Intern Med 2009;24:540-2.

8 Chan EYY, Sondorp E. Medical interventions following natural disasters: missing out on chronic medical needs. Asia Pac J Public Health 2007;19:45-51.

9 Ben-Shlomo Y, Kuh D. A life course approach to chronic disease epidemiology: conceptual models, empirical challenges and interdisciplinary perspectives. Int J Epidemiol 2002;31:285-93.

10 Kuh D, Ben-Shlomo Y, Lynch J, et al. Life course epidemiology. J Epidemiol Community Health 2003;57:778-83.

11 James SL, Abate D, Abate $\mathrm{KH}$, et al. Global, regional, and national incidence, prevalence, and years lived with disability for 354 diseases and injuries for 195 countries and territories, 1990-2017: a systematic analysis for the global burden of disease study 2017 . The Lancet 2018;392:1789-858.

12 Forouzanfar MH, Afshin A, Alexander LT, et al. Global, regional, and national comparative risk assessment of 79 behavioural, environmental and occupational, and metabolic risks or clusters of risks, 1990-2015: a systematic analysis for the global burden of disease study 2015. The Lancet 2016;388:1659-724.

13 Tan SY, Yip A. Hans Selye (1907-1982): founder of the stress theory. Singapore Med J 2018;59:170-1.

14 Baum A, Barnett ML, Wisnivesky J, et al. Association between a temporary reduction in access to health care and long-term changes in hypertension control among Veterans after a natural disaster. JAMA Network Open 2019;2:e1915111.

15 Goudet S, Griffths P, Bogin BA. Mother's body mass index as a predictor of infant's nutritional status in the post-emergency phase of a flood. Disasters 2011;35:701-19.

16 Moher D, Liberati A, Tetzlaff J, et al. Preferred reporting items for systematic reviews and meta-analyses: the PRISMA statement. Ann Intern Med 2009;151:264-9.

17 Kamel M, Smith BT, Wahi G, et al. Continuous cardiometabolic risk score definitions in early childhood: a scoping review. Obesity Reviews 2018;19:1688-99.

18 Bazoukis G, Tse G, Naka KK, et al. Impact of major earthquakes on the incidence of acute coronary syndromes - A systematic review of the literature. Hellenic J Cardiol 2018;59:262-7.

19 Covidence. Covidence - Better systematic review management, 2020. Available: https://www.covidence.org/

20 Aromataris E, Munn Z, eds. JBI manual for evidence synthesis. Adelaide, Australia: JBI, 2020. https://wiki.jbi.global/display/MANUAL

21 Kroska EB, O'Hara MW, Elgbeili G, et al. The impact of maternal flood-related stress and social support on offspring weight in early childhood. Arch Womens Ment Health 2018;21:225-33.

22 Dancause KN, Laplante DP, Hart KJ. Prenatal stress due to a natural disaster predicts adiposity in childhood: the lowa flood study. J Obes 2015;2015:1-10.

23 Dancause KN, Laplante DP, Fraser S, et al. Prenatal exposure to a natural disaster increases risk for obesity in 51/2-year-old children. Pediatr Res 2012;71:126-31.

24 Dancause KN, Veru F, Andersen RE, et al. Prenatal stress due to a natural disaster predicts insulin secretion in adolescence. Early Hum Dev 2013;89:773-6.

25 Liu GT, Dancause KN, Elgbeili G, et al. Disaster-related prenatal maternal stress explains increasing amounts of variance in body composition through childhood and adolescence: project ice storm. Environ Res 2016;150:1-7.

26 Cao-Lei L, Dancause KN, Elgbeili G, et al. Pregnant women's cognitive appraisal of a natural disaster affects their children's BMI and central adiposity via DNA methylation: Project Ice Storm. Early Hum Dev 2016;103:189-92.

27 Oni O, Harville E, Xiong X, et al. Relationships among stress coping styles and pregnancy complications among women exposed to Hurricane Katrina. J Obstet Gynecol Neonatal Nurs 2015;44:256-67.

28 Xiao J, Huang M, Zhang W, et al. The immediate and lasting impact of Hurricane sandy on pregnancy complications in eight affected counties of new York state. Sci Total Environ 2019;678:755-60.

29 Roseboom TJ, van der Meulen JHP, Ravelli ACJ, et al. Effects of prenatal exposure to the Dutch famine on adult disease in later life: an overview. Mol Cell Endocrinol 2001;185:93-8.

30 de Rooij SR, Painter RC, Holleman F, et al. The metabolic syndrome in adults prenatally exposed to the Dutch famine. Am J Clin Nutr 2007;86:1219-24.

31 Ekamper P, van Poppel F, Stein AD, et al. Prenatal famine exposure and adult mortality from cancer, cardiovascular disease, and other causes through age 63 years. Am J Epidemiol 2015;181:271-9.

32 Lumey LH, Martini LH, Myerson M, et al. No relation between coronary artery disease or electrocardiographic markers of disease in middle age and prenatal exposure to the Dutch famine of 1944-5. Heart 2012;98:1653-9.

33 Painter RC, de Rooij SR, Bossuyt PM, et al. Early onset of coronary artery disease after prenatal exposure to the Dutch famine. Am J Clin Nutr 2006;84:322-7.

34 Ravelli ACJ, van der Meulen JHP, Osmond C, et al. Obesity at the age of $50 \mathrm{Y}$ in men and women exposed to famine prenatally. Am J Clin Nutr 1999;70:811-6.

35 Stein AD, Zybert PA, van der Pal-de Bruin K, et al. Exposure to famine during gestation, size at birth, and blood pressure at age $59 \mathrm{y}$ : evidence from the dutch famine. Eur J Epidemiol 2006;21:759-65.

36 Hult M, Tornhammar P, Ueda P, et al. Hypertension, diabetes and overweight: looming legacies of the Biafran famine. PLoS One 2010;5:e13582.

37 Huang C, Li Z, Wang M, et al. Early life exposure to the 1959-1961 Chinese famine has long-term health consequences. J Nutr 2010;140:1874-8.

38 Mazumder B, Almond D, Park K, et al. Lingering prenatal effects of the 1918 influenza pandemic on cardiovascular disease. J Dev Orig Health Dis 2010;1:26-34.

39 Myrskylä M, Mehta NK, Chang VW. Early life exposure to the 1918 influenza pandemic and old-age mortality by cause of death. $A m \mathrm{~J}$ Public Health 2013;103:e83-90.

40 Bercovich E, Keinan-Boker L, Shasha SM. Long-term health effects in adults born during the holocaust. Isr Med Assoc J 2014;16:203-7. 
41 Schreier NK, Moltchanova EV, Blomstedt PA, et al. Prenatal exposure to wartime stress - long-term effect on coronary heart disease in later life. Ann Med 2011;43:555-61.

42 Sotomayor O. Fetal and infant origins of diabetes and ill health: evidence from Puerto Rico's 1928 and 1932 hurricanes. Econ Hum Biol 2013;11:281-93.

43 Dorn T, Yzermans CJ, Guijt H, et al. Disaster-related stress as a prospective risk factor for hypertension in parents of adolescent fire victims. Am J Epidemiol 2007;165:410-7.

44 Karatzias T, Yan E, Jowett S. Adverse life events and health: a population study in Hong Kong. J Psychosom Res 2015;78:173-7.

45 Lawrence WR, Lin Z, Lipton EA, et al. After the storm: short-term and long-term health effects following Superstorm sandy among the elderly. Disaster Med Public Health Prep 2019;13:28-32.

46 Vanasse A, Cohen A, Courteau J, et al. Association between floods and acute cardiovascular diseases: a population-based cohort study using a geographic information system approach. Int J Environ Res Public Health 2016;13:168.

47 Trasande L, Koshy TT, Gilbert J, et al. Cardiometabolic profiles of adolescents and young adults exposed to the world Trade center disaster. Environ Res 2018;160:107-14

48 Becquart N, Naumova E, Singh G, et al. Cardiovascular Disease Hospitalizations in Louisiana Parishes' Elderly before, during and after Hurricane Katrina. Int J Environ Res Public Health 2018;16:74.

49 Jordan HT, Stellman SD, Morabia A, et al. Cardiovascular disease hospitalizations in relation to exposure to the September 11, 2001 world Trade center disaster and posttraumatic stress disorder. J Am Heart Assoc 2013;2:e000431.

50 Kong SY, Song KJ, Shin SD, et al. Cardiovascular events after the Sewol ferry disaster, South Korea. Prehosp Disaster Med 2019;34:142-8

51 Joseph NT, Matthews KA, Myers HF. Conceptualizing health consequences of Hurricane Katrina from the perspective of socioeconomic status decline. Health Psychology 2014;33:139-46.

52 McKinney N, Houser C, Meyer-Arendt K. Direct and indirect mortality in Florida during the 2004 Hurricane season. Int J Biometeorol 2011:55:533-46.

53 Dirkzwager AJE, van der Velden PG, Grievink L, et al. Disaster-related posttraumatic stress disorder and physical health. Psychosom Med 2007;69:435-40.

54 Jiao Z, Kakoulides SV, Moscona J, et al. Effect of Hurricane Katrina on incidence of acute myocardial infarction in New Orleans three years after the storm. Am J Cardiol 2012;109:502-5.

55 Gautam S, Menachem J, Srivastav SK, et al. Effect of Hurricane Katrina on the incidence of acute coronary syndrome at a primary angioplasty center in New Orleans. Disaster Med Public Health Prep 2009;3:144-50.

56 Nagayoshi Y, Yumoto S, Sakaguchi K, et al. Heart attacks triggered by huge mud slides in mountain regions and severe flooding in inhabited areas. J Cardiol 2015;65:117-20.

57 Jordan HT, Miller-Archie SA, Cone JE, et al. Heart disease among adults exposed to the September 11, 2001 world Trade center disaster: results from the world Trade center health registry. Prev Med 2011;53:370-6.

58 Kim S, Kulkarni PA, Rajan M, et al. Hurricane sandy (new Jersey): mortality rates in the following month and quarter. Am J Public Health 2017;107:1304-7.

59 Fonseca VA, Smith H, Kuhadiya N, et al. Impact of a natura disaster on diabetes: exacerbation of disparities and long-term consequences. Diabetes Care 2009;32:1632-8.

60 Silva-Palacios F, Casanegra Al, Shapiro A, et al. Impact of tornadoes on hospital admissions for acute cardiovascular events. Thromb Res 2015;136:907-10.

61 Bich TH, Quang LN, Ha LTT, et al. Impacts of flood on health: epidemiologic evidence from Hanoi, Vietnam. Glob Health Action 2011;4:6356.
62 Huizink ACet al. Long term health complaints following the Amsterdam air disaster in police officers and fire-fighters. Occup Environ Med 2006;63:657-62.

63 Jordan HT, Brackbill RM, Cone JE, et al. Mortality among survivors of the Sept 11, 2001, world Trade center disaster: results from the world Trade center health registry cohort. The Lancet 2011;378:879-87.

64 Hendrickson LA, Vogt RL. Mortality of Kauai residents in the 12-month period following Hurricane Iniki. Am J Epidemiol 1996;144:188-91.

65 Peters MN, Katz MJ, Moscona JC, et al. Effect of Hurricane Katrina on chronobiology at onset of acute myocardial infarction during the subsequent three years. Am J Cardiol 2013;111:800-3.

66 Koroma IB, Javadi D, Hann K, et al. Non-Communicable diseases in the Western area district, Sierra Leone, following the Ebola outbreak. F1000Res 2019:8:795.

67 An K, Salyer J, Kao H-FS. Psychological strains, salivary biomarkers, and risks for coronary heart disease among Hurricane survivors. Biol Res Nurs 2015;17:311-20.

68 Lin S, Gomez MI, Gensburg L, et al. Respiratory and cardiovascular hospitalizations after the world Trade center disaster. Arch Environ Occup Health 2010;65:12-20.

69 Yu S, Alper HE, Nguyen A-M, et al. Risk of stroke among survivors of the September 11, 2001, world Trade center disaster. J Occup Environ Med 2018;60:e371-6.

70 Brackbill RM, Thorpe LE, DiGrande L, et al. Surveillance for world Trade center disaster health effects among survivors of collapsed and damaged buildings. MMWR Surveill Summ 2006;55:1-18.

71 Gerin W, Chaplin W, Schwartz JE, et al. Sustained blood pressure increase after an acute stressor: the effects of the 11 September 2001 attack on the new York City world Trade center. J Hypertens 2005;23:279-84.

72 Husarewycz MN, El-Gabalawy R, Logsetty S, et al. The association between number and type of traumatic life experiences and physical conditions in a nationally representative sample. Gen Hosp Psychiatry 2014;36:26-32.

$73 \mathrm{Ng} \mathrm{J}$, Atkin SL, Rigby AS, et al. The effect of extensive flooding in Hull on the glycaemic control of patients with diabetes: impact of flooding on glycaemic control. Diabetic Medicine 2011;28:519-24.

74 Rey G, Jougla E, Fouillet A, et al. The impact of major heat waves on all-cause and cause-specific mortality in France from 1971 to 2003. Int Arch Occup Environ Health 2007;80:615-26.

75 Moscona JC, Peters MN, Maini R, et al. The incidence, risk factors, and Chronobiology of acute myocardial infarction ten years after Hurricane Katrina. Disaster Med Public Health Prep 2019;13:217-22.

76 Thethi TK, Yau CL, Shi L, et al. Time to recovery in diabetes and comorbidities following Hurricane Katrina. Disaster Med Public Health Prep 2010;4:S33-8.

77 Schneiderman N, Ironson G, Siegel SD. Stress and health: psychological, behavioral, and biological determinants. Annu Rev Clin Psychol 2005;1:607-28.

78 Committee on Post-Disaster Recovery of a Community's Public Health M, Policy B on HS, Medicine I of. Health Care. Healthy, resilient, and sustainable communities after disasters: strategies, opportunities, and planning for recovery. Washington, DC: National Academies Press (US), 2015. https://www.ncbi.nlm.nih.gov/books/ NBK316524/

79 Puckrein GA, Egan BM, Howard G. Social and medical determinants of cardiometabolic health: the big picture. Ethn Dis;25:521-4.

80 Schultz WM, Kelli HM, Lisko JC, et al. Socioeconomic status and cardiovascular outcomes: challenges and interventions. Circulation 2018;137:2166-78

81 Mohammed SH, Habtewold TD, Birhanu MM, et al. Neighbourhood socioeconomic status and overweight/obesity: a systematic review and meta-analysis of epidemiological studies. BMJ Open 2019;9:e028238. 